THESIS

\title{
QUANTIFYING THE “AGING RESPONSE” AND NUTRIENT COMPOSITION FOR MUSCLES OF THE BEEF ROUND
}

\author{
Submitted by \\ Cheyenne L. Dixon \\ Department of Animal Sciences
}

\author{
In partial fulfillment of the requirements \\ For the degree of Master of Science \\ Colorado State University \\ Fort Collins, Colorado
}

Fall 2010

Master's Committee:

Department Chair: William R. Wailes

Advisor: Keith E. Belk

Phillip L. Chapman

J. Daryl Tatum

Dale R. Woerner 


\section{ABSTRACT OF THESIS \\ QUANTIFYING THE “AGING RESPONSE” AND NUTRIENT COMPOSITION FOR MUSCLES OF THE BEEF ROUND}

The objective of this study was to determine the optimal postmortem aging period and nutrient composition for Beef Value Cuts of the round. For the postmortem aging study, 40 USDA Select and 40 premium USDA Choice beef carcasses were selected from a commercial beef packing plant in Colorado over a 12-week period. The bottom and inside rounds were collected from both sides of each carcass for further fabrication into the following muscles: Adductor, Gastrocnemius, Gracilis, Pectineus, and Superficial digital flexor. Each pair of muscles was cut into seven steaks, approximately $2.54 \mathrm{~cm}$ in thickness, and vacuum packaged. All steaks were randomly assigned to one of the following aging periods: 2, 4, 6, 10, 14, 21, and 28 days, and placed in refrigerated storage $\left(2^{\circ} \mathrm{C}\right.$, never frozen). Upon completion of the designated aging period, steaks were removed from storage, cooked to a peak internal temperature of $72^{\circ} \mathrm{C}$, and evaluated using Warner-Bratzler shear force (WBSF). A two-way interaction was detected $(P<0.05)$ between individual muscle and postmortem aging period. The WBSF of all muscles except the Superficial digital flexor decreased with increased time of postmortem aging. Quality grade did not affect $(P>0.05)$ WBSF values for the Adductor, Gastrocnemius, Pectineus, and Superficial digital flexor muscles. Exponential 
decay models were used to predict the change in WBSF from 2 to 28 days postmortem (aging response). The Adductor, Gastrocnemius, Select Gracilis, premium Choice Gracilis, and Pectineus required 21, 14, 23, 23, and 25 days, respectively, to complete the majority of the aging response. To determine the nutrient composition of the Adductor, Gastrocnemius, Gracilis, Pectineus, Semimembranosus, and Superficial digital flexor, bottom and inside rounds were collected from 10 USDA Select and 10 premium USDA Choice carcasses, fabricated into the respective muscles, cut into $2.54 \mathrm{~cm}$ cubes, frozen ($20^{\circ} \mathrm{C}$ ), and then homogenized. The Adductor, Gracilis, Pectineus, Semimembranosus, and Superficial digital flexor were analyzed for dry matter, moisture, crude protein, and ash percentages. All muscles were evaluated for lipid percentage and fatty acid and cholesterol composition. When quality grades were combined, all muscles fell into the "extra lean" or "lean" categories specified by USDA guidelines based on the total fat, saturated fat, and cholesterol content present in each cut. Results of this study illustrate the potential for Beef Value Cuts of the round to be sold in foodservice operations and retail stores with marketing emphasis being placed on the exceptional leanness and acceptable tenderness of these cuts. 


\section{TABLE OF CONTENTS}

Abstract of Thesis ………………………………………………………..ii

Table of Contents .......................................................................................

List of Tables ............................................................................................

List of Figures............................................................................................. viii

Chapter I Introduction...........................................................................................

Chapter II $\quad$ Review of Literature ……………………........................................

Postmortem Changes in the Muscle........................................................

Proteolysis of Myofibrillar Proteins........................................................

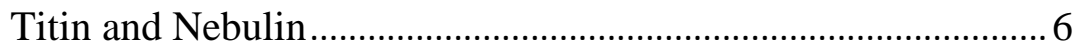

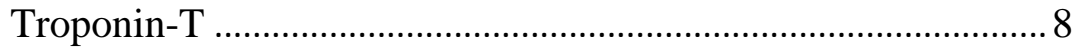

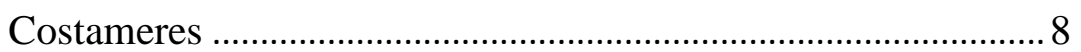

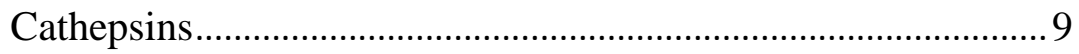

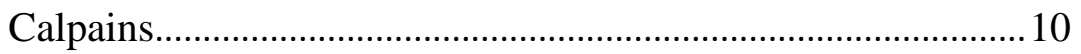

Weakening of the Actin-Myosin Cross-Bridge Interaction ...............12

Connective Tissue Degradation...........................................................14

Origins of Postmortem Tenderness....................................................16

Measuring Postmortem Tenderness ....................................................17

Management of Postmortem Tenderness ……………………….......19

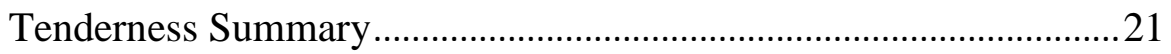

Beef in the Diet .....................................................................................22

Nutrient Database Improvement Research ………………………....25

Nutrition Summary …………………………………………..... 25

Chapter III Quantifying the “Aging Response” for Muscles of the Beef Round..........27

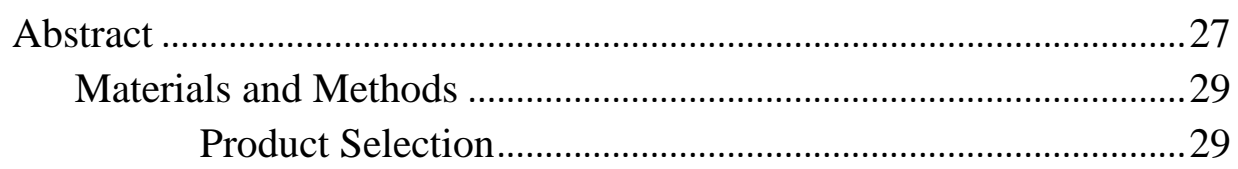


Muscle Fabrication...................................................................29

Warner-Bratzler Shear Force Determination..........................30

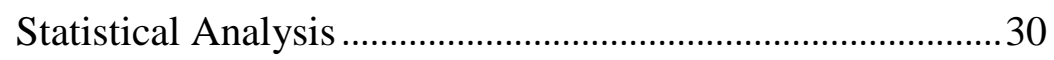

Exponential Decay Models ..........................................................31

Results and Discussion .........................................................................32

Effects of Postmortem Aging ..................................................33

Individual Muscle Tenderness ..................................................36

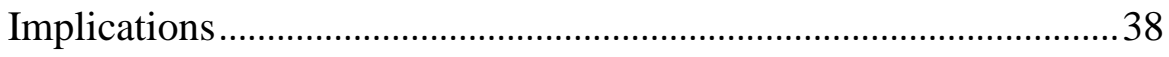

Chapter IV Muscles of the Round: Nutrient Composition of Cuts..................................55

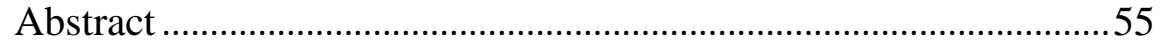

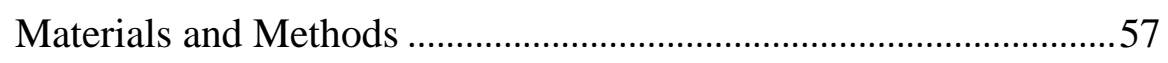

Product Selection...................................................................57

Muscle Fabrication and Homogenization .................................57

Ash Analysis .......................................................................58

Dry Matter and Moisture Analysis.........................................58

Lipid and Fatty Acid Analysis ................................................58

Protein Analysis..................................................................59

Cholesterol Analysis ...............................................................59

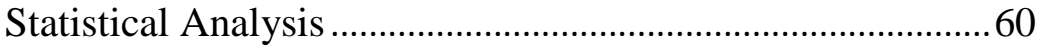

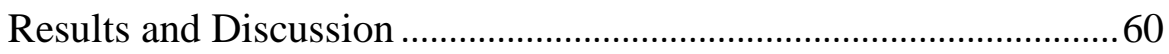

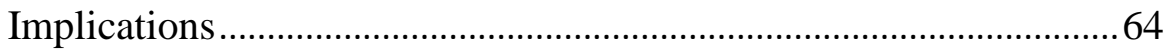

Chapter V ～Literature Cited......................................................................................71

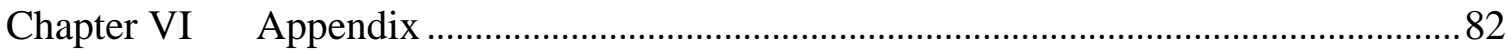

Least squares means \pm standard errors of Warner-Bratzler shear force $(\mathrm{kg})$ for four beef muscles at seven postmortem aging periods (d).

Least squares means \pm standard errors of Warner-Bratzler shear force (kg) for USDA Select and upper $2 / 3$ USDA Choice Gracilis at seven postmortem aging periods (d) ..... .84

Analysis averages of proximate, cholesterol, and fatty acid (normalized weight percentage (\%)) test standards .85 


\section{LIST OF TABLES}

Table 3.1 Simple means and standard deviations for carcass traits of the experimental sample stratified by quality grade

Table 3.2 Individual beef muscles removed from a carcass, the number of each muscle evaluated, and the subprimal from which each muscle was removed

Table 3.3 Coefficients of determination $\left(\mathrm{R}^{2}\right)$ and parameter estimates for models fitted to four beef muscles.

Table 3.4 Coefficients of determination $\left(\mathrm{R}^{2}\right)$ and parameter estimates for models fitted to USDA Select and premium USDA Choice Gracilis

Table 3.5 Rate of change in Warner-Bratzler shear force $(\mathrm{kg})$ at twelve postmortem aging periods (d) as estimated by exponential decay models fitted to four beef muscles

Table 3.6 Rate of change in Warner-Bratzler shear force $(\mathrm{kg})$ at twelve postmortem aging periods (d) as estimated by exponential decay models fitted to USDA Select and premium USDA Choice Gracilis .

Table 3.7 Warner-Bratzler shear force (WBSF) of four beef muscles at $2 \mathrm{~d}$ postmortem $(\mathrm{kg})$, the change in shear force through $28 \mathrm{~d}$ postmortem (aging response), and the percentage (\%) of that change completed at each of six postmortem aging periods

Table 3.8 Warner-Bratzler shear force (WBSF) of Gracilis at 2 d postmortem (kg), the change in shear force through $28 \mathrm{~d}$ postmortem (aging response), and the percentage (\%) of that change completed at each of six postmortem aging periods

Table 3.9 Change in shear force from 2 through $28 \mathrm{~d}$ postmortem (aging response, $\mathrm{kg}$ ) and the length of postmortem aging (d) needed for a majority of this change to occur for four beef muscles. 
Table 3.10 Change in shear force from 2 through $28 \mathrm{~d}$ postmortem (aging response, $\mathrm{kg}$ ) and the length of postmortem aging (d) needed for a majority of this change to occur for USDA Select and upper ${ }^{2} / 3$ USDA Choice Gracilis

Table 3.11 Rank of five beef muscles from lowest Warner-Bratzler shear force (WBSF) to highest WBSF at four postmortem aging periods.

Table 4.1 Simple means and standard deviations for carcass traits of the experimental sample stratified by quality grade

Table 4.2 Individual beef muscles removed from a carcass, the number of each muscle evaluated, and the subprimal from which each muscle was removed .66

Table 4.3 Means \pm SEM and p-values of raw proximate, cholesterol, and fatty acid analyses for five USDA Select and premium USDA Choice beef muscles

Table 4.4 Means \pm SEM of raw proximate, cholesterol, and fatty acid analyses for six combined USDA Select and premium USDA Choice beef muscles ...68

Table 4.5 Means \pm SEM of raw proximate and fatty acid analyses with significant quality grade effects between USDA Select and premium USDA Choice beef muscles

Table 4.6 Means \pm SEM of raw fatty acid (g/100g) analyses for six combined USDA Select and premium USDA Choice beef muscles........................................70 


\section{LIST OF FIGURES}

Figure 3.1 Least squares means \pm standard errors for Warner-Bratzler shear force (WBSF) of Adductor at seven postmortem aging points ...........................50

Figure 3.2 Least squares means \pm standard errors for Warner-Bratzler shear force (WBSF) of Gastrocnemius at seven postmortem aging points ...................51

Figure 3.3 Least squares means \pm standard errors for Warner-Bratzler shear force (WBSF) of Gracilis at seven postmortem aging points .52

Figure 3.4 Least squares means \pm standard errors for Warner-Bratzler shear force (WBSF) of Pectineus at seven postmortem aging points .53

Figure 3.5 Least squares means \pm standard errors for Warner-Bratzler shear force (WBSF) of Superficial digital flexor at seven postmortem aging point ....54 


\section{CHAPTER I}

\section{INTRODUCTION}

Using United States Department of Agriculture (USDA) data, Cattle Fax discovered a five year trend between 1993 and 1998 revealing that the wholesale value of beef ribs and loins had increased only 3 to 5\%, while the wholesale value of beef chucks, rounds, and trimmings had decreased 25 to 26\% (USDA, 2005; Von Seggern et al., 2005). This prompted the National Cattlemen’s Beef Association (NCBA) to commission a Muscle Profiling research effort to identify several muscles from the beef chuck and round that possessed desirable tenderness, flavor, and nutritional attributes and which could be marketed as single-muscle beef cuts (Von Seggern et al., 2005). The round accounts for nearly $22 \%$ of the weight of a typical beef carcass (Reuter et al., 2002), so utilization of this primal for steak or high-end cuts could significantly increase overall value of the carcass.

Researchers at Colorado State University (CSU) were commissioned by NCBA to develop aging guidelines for 17 muscles, including the newest Beef Value Cuts chosen from the Muscle Profiling studies (Gruber et al., 2006). Since most previous tenderness research had performed shear force testing after the meat product had been frozen and thawed (Davis et al., 1979; Shanks et al., 2002), and freezing has been 
shown to decrease shear values (Shanks et al., 2002), all muscles used in the Gruber et al. (2006) study were exclusively stored under refrigerated conditions $\left(2^{\circ} \mathrm{C}\right)$ and were never frozen. This provided insight into postmortem aging effects in fresh beef, independent of the effects of freezing. The study resulted in an "Aging Index" providing standardized wet-aging time recommendations for several beef muscles that could be used by packers, retailers, branded beef programs, and foodservice operations to better manage beef tenderness. Five additional round muscles (Adductor, Gastrocnemius, Gracilis, Pectineus, and Superficial digital flexor) have been selected for inclusion as Beef Value Cuts and this study was conducted to develop appropriate wet-aging time recommendations and assess the nutrient composition of those muscles. 


\section{CHAPTER II}

\section{REVIEW OF LITERATURE}

\section{Postmortem changes in the muscle}

Tenderness is the most important textural attribute of meat and one of the biggest influencers in a consumer's approval of a meat product (Szczesniak and Jorgenson, 1965; Koohmaraie, 1994). Postmortem aging has long been established as one of the most effective management practices for improving beef tenderness (Smith et al., 1978; Calkins and Seideman, 1988; Tatum et al., 1999). In general, most meat is more tender after 7 to 10 days of postmortem aging, than it is the day after slaughter (Smith et al., 1978). Calkins and Seideman (1988) found that a majority (81.1\%) of the aging response occurred during the first six days postmortem, with 4\% of tenderness increase occurring between 6 and 9 days, and the remaining 14.9\% occurring at the end of the aging period (between 9 and 14 days in the study). Few studies have evaluated tenderness within the first 24 hours following slaughter (Goll et al., 1997). Muscle ATP concentrations remain high enough for 6 to 12 hours after death to support contraction, and any attempt to shear or cook muscle with residual ATP results in severe contraction (Goll et al., 1997). When assessing muscle tenderness at the time of slaughter, Wheeler and Koohmaraie (1994) determined that ovine Longissimus muscles had intermediate shear force values immediately after 
slaughter, achieved maximum toughness at 9 to 24 hours, and became more tender during postmortem storage. It was assumed that rigor shortening was the cause of the initial toughness, and proteolytic degradation was responsible for further postmortem tenderization (Wheeler and Koohmaraie, 1994). To support this assumption, Koohmaraie et al. (1996) extracted ovine Longissimus muscles within fifteen minutes of exsanguination and clamped the muscles between metal plates to prevent muscle shortening. Results from the study showed no increase in shear force values during rigor development when the muscle was prevented from shortening, implying that initial toughness following slaughter (within 24 hours postmortem) is caused by sarcomere shortening, and that rigor-induced toughening occurs uniformly in all carcasses (Koohmaraie et al., 1996). Marsh and Leet (1966) stated that less than a $20 \%$ decrease in sarcomere length caused little or no toughening, but that 20 to $40 \%$ shortening increased toughness significantly. However, tenderness increased beyond $40 \%$ shortening and $60 \%$ shortening nearly equated the muscle to one in which no shortening occurred, possibly due to increased muscle structure disruption (Marsh and Leet, 1966). When extreme shortening occurs, the thick filaments may penetrate the z-disk, disrupting the sarcomere structure, and increasing tenderness (Goll et al., 1997). However, several studies have found no correlation between sarcomere length/shortening and tenderness (Culler et al., 1978; Parrish et al., 1979; Aberle et al., 1981). Culler et al. (1978) tested three groups of loin steaks split by tenderness ranking (tender, intermediate, and tough). No significant difference was found between the sarcomere lengths of the myofibrils of the three tenderness groups, even though differences existed among the myofibrillar fragmentation index (MFI) values 
and sensory panel tenderness and connective tissue ratings. Parrish et al. (1979)

evaluated 124 loin steaks from four different maturities of beef (A, B, C, and E) and found no significant differences among sarcomere length. Thus, postmortem tenderization is believed to originate from:

- $\quad$ Proteolyis of myofibrillar and key associated proteins

- Weakening of the actin/myosin cross-bridge interaction

- Loss of structural connective tissue integrity

\section{Proteolysis of myofibrillar proteins}

Evidence has suggested that the degradation of key myofibrillar and associated proteins is one of the primary causes of meat tenderization during postmortem storage (Goll et al., 1983; Koohmaraie, 1996). Advancements in histological technology, including the electron microscope, sodium dodecyl sulfate polyacrylamide gel electrophoresis (SDS-PAGE), and western blotting, enabled further research in the area of postmortem muscle proteolysis (Bandman and Zdanis, 1988). Even though postmortem proteolysis presumably accounts for 30 to $40 \%$ of postmortem tenderization (Goll et al., 1997), most studies agree that proteolytic degradation has a minimal effect on muscle within the first 72 hours postmortem (Goll et al., 1964; Calkins and Seideman, 1988; Koohmaraie, 1994). Myofibrillar proteins maintain the structural integrity of myofibrils; thus, proteolysis of these proteins should result in loss of myofibrillar integrity and improved tenderness (Koohmaraie, 1996). The myofibrillar fragmentation index (MFI) has been widely accepted as a method to estimate z-disk and myofibrillar degradation in postmortem muscle (Taylor et al., 1995). The MFI is a measure of the average length of myofibrils, and the relation of 
this length to tenderness (e.g. shorter myofibrils result in higher MFI, which is an indicator of increased tenderness) (Møller et al., 1973). Myofibrils are shorter in postmortem muscle than in at-death muscle, implying that myofibrils break into smaller fragments with increasing postmortem aging time (Takahashi et al., 1967; Olson et al., 1976). Myofibrils are more likely to fragment as protein hydrolysis increases, resulting in a higher MFI (Whipple et al., 1990).

Titin and Nebulin. Two of the myofibrillar cytoskeletal proteins that are thought to be highly susceptible to proteolysis and degradation during postmortem aging are the giant proteins titin and nebulin (Wang and Ramirez-Mitchell, 1983; Bandman and Zdanis, 1988).

Titin is the third most abundant protein in the myofibril, comprising approximately 10 to $15 \%$ of myofibrillar protein (Robson et al., 1984), and is the largest protein yet discovered, approximately 3,000 kDa (Huff-Lonergan et al., 1995). Titin is tightly bound to the outside shaft of the myosin filament and attaches to the zdisk at the N-terminal. Titin within the A band is inelastic, while the portion of titin in the I band is relatively elastic (Wang and Ramirez-Mitchell, 1983; Aberle et al., 2001). Titin is presumed to serve as both a template for thick filaments during myofibril and sarcomere formation and as a connector between myosin filaments and the sarcomeric z-lines (Koretz et al., 1993).

Nebulin serves as a template for assembly and/or a scaffold for stability of thin filaments, and may possibly play a role in the anchoring of thin filaments to z-lines (Aberle et al., 2001). Nebulin extends the entire length of the actin filament from the A band to the z-disk, where it attaches at the C-terminal (Aberle et al., 2001). 
Since at least one end of both titin and nebulin are attached to the z-line, they are regarded as important components of myofibrillar integrity (Robson et al., 1984; Huff-Lonergan et al., 1995). Huff-Lonergan et al. (1995) found that both titin and nebulin progressively degraded with increasing postmortem aging time. The majority of titin was degraded by 14 days, and all nebulin was degraded by 7 days. They also concluded that titin degraded more quickly in tender beef ( 7 days) than in less tender beef (14 days). This conclusion held in agreement for nebulin, with the protein being degraded by 3 days in more tender beef and by 7 days in tougher beef.

Taylor et al. (1995) used bovine Semimembranosus, Semitendinosis, and Biceps femoris muscles to determine postmortem degradation of the $\mathrm{N}_{2}$ lines (areas where titin and nebulin filaments unite with the z-disk). Contrary to the belief that an increase in MFI during postmortem aging is caused by z-disk weakening, Taylor et al. (1995) observed no z-disk breakage; it was determined that approximately 25\% of muscle nebulin is degraded during the first 24 hours postmortem and that titin is entirely degraded between 24 and 72 hours postmortem. Postmortem degradation of nebulin was shown to occur at one end, rather than the center, of the polypeptide. If the degradation occurred at the C-terminal end (z-disk location), it would contribute to the weakening of the z-disk attachment (Taylor et al., 1995). The transition of $\mathrm{T}_{1}$ titin to $\mathrm{T}_{2}$ titin (degraded form) results from cleavage of the titin polypeptide from the $\mathrm{N}$-terminal at the z-disk attachment. It is likely that the combined nebulin/titin degradation also caused the increased fragility of the I-band during postmortem storage (Taylor et al., 1995). The z-disk weakening was presumed to occur primarily because of nebulin and titin degradation, as the two major z-disk proteins, $\alpha$-actin and 
$\alpha$-actinin, were not degraded during the first 14 to 18 days postmortem (Taylor et al., 1995).

Troponin-T. Troponin-T is responsible for binding troponin I and troponin C to tropomyosin, and thus, to the thin filaments (Hitchcock et al., 1973). It is generally accepted that the $30 \mathrm{kDa}$ component of PAGE during protein separation that appears in muscle during postmortem aging is the degraded form of troponin-T (Olson and Parrish, 1977; Robson et al., 1984; Ho et al., 1994). As postmortem aging time increased, Huff-Lonergan et al. (1995) observed the intensification of the $30 \mathrm{kDa}$ component, but at varying rates among different animals; the component appeared quicker in more tender samples than in less tender samples. Penny and Dransfield (1979) demonstrated a positive correlation between the loss of troponin-T and an increase in tenderness in Longissimus dorsi and Semitendinosus muscles. Hence, research suggests troponin-T likely plays a supportive role in the structure of the myofibrils, and degradation of it into the $30 \mathrm{kDa}$ PAGE component could result in increased tenderness.

Costameres. Costameres are filamentous structures that link myofibrils to the sarcolemma (Craig and Pardo, 1983) and include $\gamma$-actin, vinculin, $\beta$-spectrin, and talin. The intermediate filament proteins, desmin and vimentin, also play a structural function, but desmin appears to have the biggest role in tenderization (Taylor et al., 1995). Therefore, it is reasonable to conclude that degradation of these structures would significantly weaken the overall structure of the muscle. All of the costameres, except $\gamma$-actin, are susceptible to rapid degradation by the calpain system (Cottin et al., 1992). Costamere structural integrity is lost within the first 24 to 72 hours 
postmortem, paralleling the degradation of the $\mathrm{N}_{2}$ lines (Taylor et al., 1995). Even though desmin accounts for less than $0.2 \%$ of skeletal muscle protein (Robson et al., 1984), the protein probably serves to connect the z-lines of adjacent myofibrils (O’Shea et al., 1981; Richardson et al., 1981). Robson et al. (1984) removed Semitendinosus muscles within 10 minutes of death and tested for protein levels at 0 , 1, and 7 days postmortem. A small decrease (approximately 10 to 25\%) in the proportion of desmin occurred by one day postmortem, but a much larger decrease in the protein occurred by the seventh day, suggesting partial responsibility for physical changes within the muscle that resulted in increased tenderness. However, Whipple et al. (1990) did not find desmin degradation linked to tenderness when studying varying crossbreeds of Bos taurus and Bos indicus cattle.

The two proteolytic systems thought initially to be responsible for the majority of myofibrillar proteolysis included lysosomal proteases, primarily cathepsins, and calcium dependent proteases (CDP), or calpains (Dutson; 1983; Goll et al., 1983; Koohmaraie, 1988). In order for a protease to be involved in postmortem tenderization, it must be located inside the skeletal muscle cell, have the capability to reproduce postmortem changes in an in-vitro environment in myofibrils, and have access to myofibrils in tissue (Koohmaraie, 1988).

Cathepsins. Cathepsins are extremely active cysteine proteases that degrade actin, myosin, and $\alpha$-actinin, the latter being a major protein involved in z-disk structure and its subsequent degradation (Goll et al., 1991). Cathepsin activity is believed to be limited to frozen tissues or aging above temperatures of $16^{\circ} \mathrm{C}$, with cathepsins $\mathrm{L}, \mathrm{H}$, and $\mathrm{B}$ being responsible for the majority of degradation, respectively 
(Goll et al., 1983). Because lysosomal enzymes, primarily cathepsins, have an affinity for acidic environments, it may be possible for cathepsins to continue proteolytic activity after day 1 postmortem, when muscle $\mathrm{pH}$ has decreased (Calkins and Seideman, 1988). Cathepsin B and $\mathrm{H}$ activity was found to be strongly correlated to a decrease in shear force between 3 and 9 days postmortem in 15 bulls and steers analyzed for proteolytic activity (Calkins and Seideman, 1988). No correlation was found between the activity of either cathepsin and the change in shear force between 1 and 3 days postmortem, indicating that other enzymatic processes were more active during that time. However, some studies (Koohmaraie et al., 1988a; Uytterhaegen et al., 1994) observed minimal changes in shear force values or myofibrillar protein levels when cathepsin inhibitors (B, D, H, and L) were added to muscle samples, suggesting a minimal role in postmortem tenderization. Goll et al. (1991) agreed that cathepsins had a minor effect on myofibrillar proteins in muscle stored at 2 to $4^{\circ} \mathrm{C}$. However, when muscle is stored at $25^{\circ} \mathrm{C}$ or higher, z-disk, myosin, actin, and $\alpha$ actinin degradation occurs, presumably from catheptic degradation (Goll et al., 1991). This form of proteolysis can be unfavorable, as significant actin-myosin degradation can result in extremely soft textured beef (Goll et al., 1991).

Calpains. Calpains are cysteine proteases that require calcium and a neutral $\mathrm{pH}$ for optimum activity (Calkins and Seideman, 1988). Goll et al. (1991) attributed 90\% of the postmortem tenderization that occurs in muscle between 2 and $4^{\circ} \mathrm{C}$ to calpain proteolysis. CDP-I ( $\mu$-calpain) and CDP-II (m-calpain) were named for the micromolar and millimolar concentrations of $\mathrm{Ca}^{2+}$ that each require for activity, respectively. Animals with a high level of calpain inhibitors, or calpastatins, have a 
decreased ability to enact early postmortem proteolysis, resulting in tougher beef (Whipple et al., 1990; O’Connor et al., 1997). When O’Connor et al. (1997) analyzed shear force values and 24 hour calpastatin levels in 575 three-eighth Bos indicus and 100\% Bos taurus cattle, the Bos indicus steers had higher Longissimus calpastatin activities than Bos taurus steers. When WBSF values were compared, Bos indicus and Bos taurus cattle had similar mean WBSF values on day-one postmortem. However, the Bos taurus beef exhibited a much faster rate of tenderization from 1 to 4 days postmortem with substantially lower mean WBSF values at 4, 7, 14, 21, and 35 days of aging (O’Connor et al., 1997). The slower rate of tenderization during the initial seven days postmortem in the Bos indicus cattle was associated with higher calpastatin activities in the muscle.

Unlike cathepsins and other proteolytic enzymes, calpains do not degrade actin and myosin (Goll et al., 1991). Calkins and Seideman (1988) reported that samples with increased levels of $\mu$-calpain had lower shear force values. Since Koohmaraie et al. (1987) revealed that $\mu$-calpain activity drops approximately $50 \%$ by the first day postmortem, it can be assumed that this enzyme is primarily responsible for the tenderness increase between exsanguination and day 1 postmortem. During onset of rigor mortis, calcium is released from the sarcoplasmic reticulum and muscle $\mathrm{pH}$ has not yet decreased, providing a favorable environment for CDP activity (Calkins and Seideman, 1988). Calpains are responsible for the degradation of the $\mathrm{N}_{2}$ lines and costameres, all of which are important structural components of the muscle (Goll et al., 1991). Koohmaraie et al. (1988a) evaluated the MFI of muscle samples immersed in one of the following solutions: buffer (Tris-acetate), buffer + EDTA, buffer + 
EGTA, and buffer $+\mathrm{CaCl}_{2}$. Solutions of EDTA and EGTA are chelators of divalent and $\mathrm{Ca}^{++}$ions, respectively, and resulted in the lowest MFI values of all groups tested, indicating decreased tenderness. At seven days postmortem, the calcium group exhibited a ten point higher MFI value than the control group and a 45 point MFI increase over the chelator groups (Koohmaraie et al., 1988a). When Uytterhaegen et al. (1994) applied various calpain inhibitors to intact muscle samples, all inhibitors resulted in increased shear force values and higher residual amounts of titin and troponin-T. Uytterhaegen et al. (1994) also reported increased calcium-induced calpain activity coinciding with decreased amounts of titin, troponin-T, and filamin

with the addition of $\mathrm{Ca}^{2+}(0.3 \mathrm{M})$ to the muscles. Koohmaraie et al. (1988b) reported that the infusion of ovine carcasses with $\mathrm{CaCl}_{2}$ resulted in completion of myofibrillar protein changes within 24 hours postmortem, compared to the three to seven days required for similar changes to occur within the non-treated group. The increased tenderness resulting from the addition of calcium ions demonstrates the efficacy of CDP-mediated proteolysis in muscle during postmortem storage.

\section{Weakening of the actin-myosin cross-bridge interaction}

While ATP muscle concentrations start to decrease during postmortem storage, the myofibrils will attempt to contract, transitioning from a resting (weak) to contractile (strong) actin/myosin cross-bridge state (Goll et al., 1997). This transition may be what Wheeler and Koohmaraie (1994) noted in the initial toughness of the ovine muscles that was described previously. When ATP concentration is exhausted, the energy needed for relaxation will diminish, and the muscle becomes "locked" in 
the strong cross-bridge state (rigor). Evidence to support this postmortem reaction includes the following changes to the actin/myosin cross-bridge (Goll et al., 1997):

- Inability to maintain isometric tension

- Increase in extensibility

- Lengthening of rigor-shortened sarcomeres

Busch et al. (1967) noted a loss of isometric tension in bovine Psoas major and Semitendinosus muscles stored at $2^{\circ} \mathrm{C}$, and by 72 hours postmortem, tension values were half of what maximum tension originally was in each muscle. Busch et al. (1972) compared the effects of adding $\mathrm{Ca}^{2+}$ and $\mathrm{Ca}^{2+}$ chelators (EGTA and EDTA) to rabbit Psoas strips and reported that $\mathrm{Ca}^{2+}$ chelator strips maintained maximum isometric tension for 24 to 48 hours postmortem. The $\mathrm{Ca}^{2+}$ and control strips returned to zero tension development within 7 and 24 to 30 hours, respectively, indicating that $\mathrm{Ca}^{2+}$ has a large effect on the rate of isometric tension development loss (Busch et al., 1972). Dransfield et al. (1986) continuously monitored the extensibility and irreversible lengthening in the direction of the muscle fibers in M. pectoralis profundus muscles from 2 hours to 10 days postmortem. Following tensile testing that cycled between low $\left(0.1 \mathrm{Ncm}^{-2}\right)$ and high $\left(0.3\right.$ to $\left.2.1 \mathrm{Ncm}^{-2}\right)$ "stress," lengthening appeared to occur earlier at higher post-rigor temperatures, ranging from 4 hours at $25^{\circ} \mathrm{C}$ to 244 hours at $1^{\circ} \mathrm{C}$. Overall, the muscles increased slightly in extensibility and lengthened by $40 \%$. Approximately $80 \%$ of the tenderization witnessed in each muscle occurred by the time lengthening of the muscle had taken place. Histological images of the muscle fibers showed fractures occurring between the A bands of the myofibrils, with the average distance between fractures spanning five to eight 
sarcomeres (Dransfield et al., 1986). Etherington et al. (1987) also found that myofibril fracturing occurred within the I bands of beef $M$. pectoralis profundus samples that were tension tested between $0.1 \mathrm{Ncm}$ and $1.2 \mathrm{Ncm}$. In agreement with Dransfield et al. (1986), a distance of approximately five sarcomeres was found to encompass the space between each fracture. Stromer et al. (1967) measured sarcomere length of beef Semitendinosus muscles at various time points and temperatures and reported an increase in sarcomere length of 1.2 to $1.8 \mu$ from 24 to 312 hours postmortem. Stromer et al. (1967) observed displacement of thick filament bundles that migrated either to the right or left of the A band center. For myosin displacement to occur, thin filaments would need to be stretched or actin-myosin cross-bridges would need to be broken (Stromer et al., 1967). The researchers in this study hypothesized that disruption of the cross-bridges possibly occurred at the M line, because if myosin only interacted with actin on one side of the $\mathrm{H}$ zone, total displacement would not be observed. The state of the actin-myosin cross-bridges during postmortem aging is affected by numerous factors, especially temperature, but it can be assumed that degradation/breakage of the cross-bridges would result in postmortem tenderization.

\section{Connective tissue degradation}

Early studies suggested that the concentration and solubility of connective tissue, primarily collagen, in postmortem muscle was not affected by postmortem aging (Pierson and Fox, 1976; Chizzolini et al., 1977). Nishimura et al. (1995) used an improved scanning electron microscopy technique to view changes in the endomysium and perimysium of intramuscular connective tissue in beef muscle that 
was aged for 28 days. Minimal changes were seen during the first 10 days postmortem, but structural changes were clearly evident by day 14 . When magnified, the endomysium and perimysium had degraded into loosely aligned collagen fibrils, indicating that structural weakening had occurred due to the dissociation of collagen fibrils from endomysial sheaths and perimysial sheets. When shear force values were compared to the structural changes occurring in the muscle, tenderness increased rapidly during the first 10 days, and then gradually increased during the remaining 18 days. Similar results were reported by Nishimura et al. (1998), but neither study could identify the primary cause of the connective tissue degradation. Greaser (1997) listed the following as possible mechanisms for weakening of connective tissue in postmortem muscle:

- Catheptic enzymes and glucuronidases from muscle fibers

- Elastase from neutrophils

- Matrix metalloproteinases

- Plasmin from residual blood

Feidt et al. (1996) reported increased levels of free hydroxyproline in postmortem muscle, an amino acid found only in collagen and elastin. Therefore, it was reasoned that the release of hydroxyproline in postmortem muscle might be attributed to the breakdown of collagen molecules (Feidt et al., 1996). Nishimura et al. $(1995,1998)$ attributed the initial rapid decline in toughness to myofibrillar changes within the muscle, and the later, gradual decline in toughness to connective tissue degradation, emphasizing this process as a key component of extended postmortem aging. 


\section{Origins of postmortem tenderness}

Numerous factors influence the rate of postmortem tenderization, including the extent of sarcomere shortening that has occurred during rigor and the rate of subsequent weakening of the actin/myosin cross-bridge interaction within the first 72 hours postmortem (Goll et al., 1997). A majority of the initial, rapid changes in postmortem tenderization under refrigerated temperatures can also be attributed to calcium-dependent proteases. At refrigerated temperatures, the catheptic system plays a minor, if any, role in postmortem tenderization. It is likely that the majority of extended postmortem tenderization occurs from the weakening of connective tissue integrity. This highlights the key components of early and extended postmortem tenderization processes.

Bratcher et al. (2005) reported significant quality grade differences in tenderness between USDA Select and premium Choice Infraspinatus, Triceps brachii - lateral and long head, Serratus ventralis, Complexus, Splenius, Rhomboideus, Vastus lateralis, and Rectus femoris muscles. Averaged across all muscles, grade only influenced shear force values by about 5\%, with the largest grade effect occurring at seven days postmortem. Bratcher et al. (2005) found no interaction between individual muscles and aging, but Gruber et al. (2006) reported a significant interaction between individual muscle, quality grade, and aging period in a study conducted on 17 USDA Select and premium Choice muscles. However, numerous studies have found a weak correlation between degree of marbling and tenderness rating (determined by shear force and/or sensory testing), especially in muscles that 
have limited marbling, such as those from the round (Smith et al., 1969; Neely et al., 1998).

\section{Measuring postmortem tenderness}

Due to the ease of fabrication from the carcass, and its increased variability between animals, the Longissimus muscle has long been used for measuring tenderness among individual animals (Shackelford et al., 1995; 1997). Smith et al. (1978) reported that the tenderness (shear force) of the Longissimus muscle from the rib was significantly related to the tenderness of muscles from broiled or roasted cuts from the chuck, rib, loin, and round. However, the tenderness of this muscle has been shown to be a weak to moderate indicator of tenderness in the rest of the carcass (Shackelford et al., 1995; 1999). Individual muscle tenderness has been shown to vary greatly, as demonstrated by Ramsbottom and Strandine (1948), who reported a range from 3.22 to $7.39 \mathrm{~kg}$ (WBSF) in fifty beef muscles, aged five days, from each primal of the carcass. Smith et al. (1978) performed WBSF testing on 20 muscles from the chuck, rib, loin, and round and observed a range from 2.2 to $5.0 \mathrm{~kg}$ after 14 days of postmortem aging.

Warner-Bratzler shear force (WBSF) and slice shear force (SSF) are two forms of shear force testing commonly utilized for laboratory measurements of tenderness. To perform WBSF, a core (usually $1.27 \mathrm{~cm}$ ) is removed parallel to the muscle fiber orientation after a muscle has been cooked and allowed to equilibrate to an ambient room temperature or refrigerated temperature for 2 to 24 hours (Crouse and Koohmaraie, 1990; Wheeler et al., 1994). Peak shear force (kg) of the cores can be measured either with a Warner-Bratzler apparatus (G.R. Electrical Manufacturing 
Company, Manhattan, KS) or an Instron Testing Machine (Instron, Corp., Canton, MA) (Wheeler et al., 1994).

To perform SSF, a $1 \mathrm{~cm}$ thick, $5 \mathrm{~cm}$ long slice must be removed from the lateral end of a Longissimus steak (Shackelford et al., 1999). This involves using a double bladed knife, spaced $1 \mathrm{~cm}$ apart, to cut at a $45^{\circ}$ angle parallel to the muscle fibers (Shackelford et al., 1999). Peak shear force (kg) is determined using a flat, bluntended blade on an Instron Testing Machine (Shackelford et al., 1999). Thickness of WBSF and SSF testing blades are the same $(1.016 \mathrm{~mm})$ as is the degree of bevel (half-round), but the WBSF crosshead speed is $200 \mathrm{~mm} / \mathrm{min}$ versus the faster, 500 $\mathrm{mm} / \mathrm{min}$ speed used for SSF (Shackelford et al., 1999).

Another important aspect of shear force testing is choosing the appropriate endpoint temperature, regardless of whether or not an electric grill or broiler, impingement oven, or belt grill is used for cooking. Cover et al. (1962) and Ritchey and Hostetler (1965) reported a significant difference between WBSF values when peak internal cooking temperatures ranged from 61 to $80^{\circ} \mathrm{C}$. There was no significant difference in WBSF values when the steaks reached a peak internal temperature of 68 to $74^{\circ} \mathrm{C}$ (Ritchey and Hostetler, 1965). Numerous studies have reported results similar to the aforementioned studies and have recommended end-point temperatures of 60 to $70^{\circ} \mathrm{C}$ to better match consumer preferences in degree of doneness and reduce shear force variability (Parrish et al., 1973; Cross et al., 1976).

Various studies have determined "threshold levels” for correlating shear force values with consumer acceptance. Miller et al. (2001) stated that a tenderness threshold of < 3.0, 3.0 to 4.3 , and $>4.9 \mathrm{~kg}$ (WBSF) would result in 100, 93, and 25\% 
consumer satisfaction for beef top loin steaks. Additionally, it was reported that when tenderness decreases from “slightly tender” (4.3 kg) to “slightly tough” (4.9 kg), consumer acceptability decreases from 86 to 59\%. Using trained taste panels to determine WBSF “threshold values,” Shackelford et al. (1991) indicated that values of 4.6 and $3.9 \mathrm{~kg}$ would have a $50 \%$ and $68 \%$ chance, respectively, to be rated “slightly tender” by consumers. Platter et al. (2003) reported similar values of 4.4 and 3.7 kg to have a "slightly tender” consumer acceptance of 50 and 68\%, respectively.

A third form of tenderness determination involves the use of a trained sensory panel. Although more subjective, some researchers claim that a human panel can detect differences between connective tissue and muscle fibers, while the presence of connective tissue in a shear sample might skew or obscure the results received using a WBSF apparatus (Hostetler et al., 1973). Bratzler and Smith (1963) reported correlation coefficients between shear force values and sensory panel ratings ranging from $r=-.38$ to $r=-.75$ for beef ribs, shortloins, and rounds, but Otremba et al. (1999) stated that correlations between the two tests were dependent on blade type and coring method (fiber orientation).

\section{Management of postmortem tenderness}

Postmortem aging has long been established as one of the most effective management practices for improving beef tenderness (Smith et al., 1978; Calkins and Seideman, 1988; Tatum et al., 1999). Numerous tenderness studies have been conducted to determine the appropriate aging period for certain muscles to meet a desired level of tenderness. Smith et al. (1978) stated that aging a USDA Choice carcass for 11 days will optimize tenderness, flavor, and overall palatability in most 
muscles from the chuck, rib, loin, and round when the cuts are oven-broiled or roasted. In the same study, Smith et al. (1978) reported that five to eight days of postmortem aging was required for the following muscles of the round to reach maximum tenderization: Biceps femoris, Semimembranosus, Semitendinosus, Rectus femoris, Vastus lateralis, and Vastus medialis. It was later recommended by Gruber et al. (2006) that the aforementioned round muscles be aged 20 to 26 days for USDA Select cuts and 6 to 21 days for premium USDA Choice muscles. Extended postmortem aging is crucial for cattle with a Bos indicus genetic influence, which have been shown to require a longer postmortem aging period to compensate for the increased calpastatin activities in the muscle during the initial stages of postmortem tenderization (O’Connor et al., 1997). Actual muscle aging time in the industry can vary greatly however, as evidenced by George et al. (1999), who reported postmortem aging periods for beef loin steaks ranging from 2 to 91 days in eight U.S. cities, with the average being 20 days. The availability of steaks at a retail outlet in less than seven days of postmortem aging could potentially increase the chance of a consumer purchasing a cut with less than desirable tenderness (George et al., 1999). It was recommended by George et al. (1999) that a compilation of recommended aging values be created to prevent any short-aged beef from reaching the supermarket before it is properly aged. By identifying the minimum aging period required for certain retail beef cuts to reach an optimal level of tenderness, beef eating satisfaction could be increased without having to keep meat products on hand longer than necessary. 


\section{Tenderness Summary}

Using the threshold level of $4.6 \mathrm{~kg}$ established by Shackelford et al. (1991), Boleman et al. (1997) developed three categories of tenderness to determine consumer perceptions of beef top loin steaks of a known shear force. The established categories were labeled Red (tender), White (intermediate), and Blue (tough) with a corresponding WBSF kg range of 2.27 to $3.58 \mathrm{~kg}, 4.08$ to $5.40 \mathrm{~kg}$, and 5.90 to 7.21 kg, respectively. When the shear force values weren't known, overall satisfaction was highest for the Red category, but no difference was detected between the White and Blue categories. However, consumers were able to detect tenderness differences between all three categories. The final two stages of the process allowed the consumers to purchase steaks from each color group. When consumers were informed of the shear force value ranges corresponding to each color, $94.6 \%$ purchased steaks from the "tender” group versus 55.3\% who bought steaks from the "tender” group when they could see the steaks in a retail case, but weren't informed of the shear force ranges (Boleman et al., 1997). This study highlighted the fact that consumers are able to differentiate between tough and tender beef and are willing to pay more for increased tenderness, which is also in agreement with later studies (Miller et al., 2001; Platter et al., 2005). As a result, it is important for the beef industry, from packer to retailer and foodservice operator, to be able to properly manage beef products to maximize tenderness and, therefore, increase beef eating satisfaction in the most time-efficient manner possible. The source of postmortem tenderization stems from numerous changes within the muscle structure, but postmortem aging has been shown to be one of the most effective techniques to maximize tenderness in 
beef. Studies have recommended various aging periods to maximize tenderness, but many of these recommendations focused on whole primals, or even the whole carcass, without regard to individual muscles (Smith et al., 1978). Individual muscle tenderness has been shown to vary greatly, and the need arose to determine an optimal aging period for each muscle. Gruber et al. (2006) released a set of recommendations that outlined the optimal aging period for 17 USDA Select and premium Choice beef muscles. Since most previous tenderness research had performed shear force testing after the meat product had been frozen and thawed (Davis et al., 1979; Shanks et al., 2002), and freezing has been shown to decrease shear values (Shanks et al., 2002), all muscles used in the study were exclusively stored and aged under refrigerated conditions $\left(2^{\circ} \mathrm{C}\right)$ and never frozen to better match industry practices. Tenderness is one of the biggest influencers in a consumer's approval of a meat product (Szczesniak and Jorgenson, 1965; Koohmaraie, 1994), and with the use of such aging data, packers, branded beef programs, retailers, and foodservice operators can better manage their products to increase beef sensory satisfaction.

\section{Beef in the diet}

According to USDA guidelines (2008), a $100 \mathrm{~g}$ serving of beef qualifies as "extra lean" if it has less than $5 \mathrm{~g}$ of total fat, $2 \mathrm{~g}$ or less of saturated fat, and less than $95 \mathrm{mg}$ of cholesterol. It qualifies as "lean" if it has less than $10 \mathrm{~g}$ of total fat, $4.5 \mathrm{~g}$ or less of saturated fat, and less than $95 \mathrm{mg}$ of cholesterol. Currently, there are 29 beef cuts that fall into these categories, allowing for lean beef to be included as an integral part of a healthy diet (USDA, 2007). 
Despite various claims regarding a link between red meat consumption and cancer, no clear mechanisms have been established as contributing to cancer (Alexander and Cushing, 2010). Various meat-associated factors have been theorized to contribute to cancer development, such as cooking meat at high temperatures (Cross et al., 2010), use of nitrate and nitrite during processed meat production (Santarelli et al., 2008), and intake of animal fat (Willett et al., 1990). Alexander and Cushing (2010) analyzed 35 studies pertaining to red meat intake and colorectal cancer, and found no sufficient epidemiological evidence to support an association between the two factors. It was questioned whether the connection between increased red meat consumption and a Western lifestyle, characterized by factors such as a high body mass index, frequent smoking, lack of physical activity, and high alcohol intake, was to blame for the proposed meat and cancer connection (Alexander and Cushing, 2010). Given the frequent concurrence that each of these factors has in a Western lifestyle, it would be impossible to assess the effects that each factor may individually have on cancer risk (Huxley et al., 2009).

One of the components in beef hypothesized to have an anti-carcinogenic effect, along with positive effects on cardiovascular health, body fat composition, and other potential health benefits, are conjugated linoleic acids (CLA) (Ip et al., 2002; Lee et al., 2005). Such CLA are isomeric forms of linoleic acid (C18:2) with the double bonds separated by a single bond, giving these fatty acids unique physical and chemical properties (Stipanuk, 2000). Such CLA are produced in the rumen, and make beef fat one of the richest natural sources of CLA (Chin et al., 1992; Stipanuk, 2000). Even though many studies are inconclusive with regard to the health benefits 
of CLA (Wahle et al., 2004; Bhattacharya et al., 2006), there are significant findings to warrant more research. Grass-fed cattle tend to have a greater concentration of CLA than grain-finished cattle (French et al., 2000; Leheska et al., 2008), but the difference is not significant in regards to human health (CBB, 2008).

Current data do not suggest a significant difference in nutrient value between conventional, natural, grass-fed, and organic beef (CBB, 2008). Leheska et al. (2008) compared the effects of conventional and grass-feeding systems on the nutrient composition of ground beef and strip steaks. The conventionally fed beef strip loins contained 45.1, 46.2, and $2.77 \mathrm{~g} / 100 \mathrm{~g}$ of saturated fat (SFA), monounsaturated fat (MUFA), and polyunsaturated fat (PUFA), respectively. The grass fed beef strip loins possessed a greater amount of SFA, but a lower concentration of MUFA, 48.8 and $42.5 \mathrm{~g} / 100 \mathrm{~g}$, respectively. The difference in SFA concentration was primarily due to a greater concentration of stearic acid in the grass fed beef (Leheska et al., 2008). Stearic acid has been shown to have no effect on blood cholesterol, unlike other SFA that increase serum cholesterol, such as myristic and and palmitic acids (Hegsted et al., 1965; Keys et al., 1965). Monounsaturated fatty acids, such as oleic acid, typically make up half of beef fat (Leheska et al., 2008) and have been shown to exude beneficial health effects on LDL cholesterol levels and other cardiovascular disease (CVD) risk factors (Kris-Etherton et al., 1999). Consumption of beef, regardless of the feeding system, provides an excellent source of zinc, vitamin B12, and selenium, and a good source of vitamin B6 and iron (USDA, 2006). Additionally, an analysis of the dietary sources of nutrients of American adults from 1994 to 1996 showed that beef was the most common source of 
protein in the diet, comprising approximately $17 \%$ of total protein into the diet (Cotton et al., 2004).

\section{Nutrient Database Improvement research}

The United States Department of Agriculture (USDA) National Nutrient Database for Standard Reference (SR) is the premier database in the country used for food policy, research, and to monitor the nutrient intake of Americans (CBB and NCBA, 2009). The SR serves as the authoritative source of meat nutrient composition for the USDA Food Safety and Inspection Service (FSIS) to monitor food safety regulations and labeling policies for meats (CBB and NCBA, 2009). There are nearly 650 beef product listings in the SR currently, with approximately 125 of those referring to cuts from the round (USDA, 2004). Because of the SR's broad impact domestically and internationally, maintaining current data is crucial for the meat industry. Thus, the Nutrient Database Improvement (NDI) project was created to procure specific beef nutrient data (fat, moisture, protein, ash, fatty acid, cholesterol, vitamin, and amino acid analyses) and nutrient retention and cooking yields (CBB and NCBA, 2009). Values for all cuts of the carcass will eventually be updated in the SR, but certain cuts have been given priority, such as those representing the greatest percentage of beef retail sales, cuts on the FSIS mandatory labeling list, and the new Value Added Beef Cuts created by Beef Checkoff funded research (CBB and NCBA, 2009).

\section{Nutrition Summary}

The data in the updated SR show a 20\% decrease in the amount of fat in beef cuts since the early 1980's (CBB and NCBA, 2009). The amount of fat in beef cuts 
has decreased significantly due to closer trim levels and modified fabrication styles, but some of the outdated information in the SR does not reflect these changes. To promote beef, especially "lean beef," as an important component of a healthy diet, it is crucial to have the proper, updated information represented in the most authoritative nutrient database available. With continued revisions to the SR, and further research into developing new lean cuts, the beef industry can continue to promote the health benefits of incorporating beef into the diet. 


\title{
CHAPTER III
}

\section{QUANTIFYING THE “AGING RESPONSE” FOR MUSCLES OF THE BEEF ROUND}

\begin{abstract}
The objective of this study was to determine the optimal postmortem aging period for five Beef Value Cuts of the round. Forty USDA Select and 40 premium USDA Choice beef carcasses were selected from a commercial beef packing plant in Colorado over a 12-week period. The bottom (Gooseneck) and inside rounds were collected from both sides of the carcass for further fabrication into the following muscles: Adductor, Gastrocnemius, Gracilis, Pectineus, and Superficial digital flexor. Each pair of muscles was cut into seven steaks, approximately $2.54 \mathrm{~cm}$ in thickness. Each steak was vacuum packaged, randomly assigned to one of 7 aging periods (2, 4, $6,10,14,21$, and 28 days), and then placed into refrigerated storage $\left(2^{\circ} \mathrm{C}\right.$, never frozen). Upon completion of each designated aging period, steaks were removed from storage, cooked to a peak internal temperature of $72^{\circ} \mathrm{C}$, and evaluated using WarnerBratzler shear force (WBSF). A two-way interaction was detected $(P<0.05)$ between individual muscle and postmortem aging period. The WBSF of all muscles except the
\end{abstract}


Superficial digital flexor decreased with increased time of postmortem aging. Quality grade did not affect $(P>0.05)$ WBSF for the Adductor, Gastrocnemius, Pectineus, and Superficial digital flexor, so all results are presented for these muscles as a combination of USDA Select and premium USDA Choice samples. Exponential decay models were used to predict the mean change in WBSF from 2 to 28 days postmortem (aging response). Aging responses were assigned using the same standards Gruber et al. (2006) established and are as follows: $\geq 2.2 \mathrm{~kg}$ (high), 2.1 to $1.8 \mathrm{~kg}$ (moderately high), 1.7 to $1.1 \mathrm{~kg}$ (moderate), 1.0 to $0.7 \mathrm{~kg}$ (moderately low), and $\leq 0.6 \mathrm{~kg}$ (low). The Adductor, Gastrocnemius, and Pectineus each had a moderately low aging response (1.0 to $0.7 \mathrm{~kg}$ change) and the Select and premium Choice Gracilis experienced a moderately high response (2.1 to $1.8 \mathrm{~kg}$ change). The Pectineus was the most tender muscle, presenting the lowest WBSF throughout the 28 day aging period, but required the longest aging period (25 days) to complete the majority of the aging response ( $\leq 0.1 \mathrm{~kg}$ of aging response remaining). Even though the Gracilis was the only muscle to express a difference in WBSF between quality grades $(P<0.05)$, the optimal aging period was 23 days for both Select and premium Choice muscles. The Adductor and Gastrocnemius required 21 and 14 days, respectively, to complete a majority of the aging response. Results from this study suggest that tenderness varies among individual muscles from differing anatomical locations within the beef carcass and postmortem aging times, and with the proper aging treatment, beef eating quality can be improved. 


\section{Materials and Methods}

Product Selection

USDA Select $(n=40)$ and premium USDA Choice $(n=40$; the upper two-thirds of the Choice grade) beef carcasses were identified over a 12-week period from a commercial beef packing plant located in northeastern Colorado for use in this study (Table 3.1). At two days postmortem, carcasses were individually identified and followed through fabrication to obtain the inside round (IMPS 168) and bottom (Gooseneck) round (IMPS 171F) (USDA, 1996) from both sides of the carcass (Table

3.2). The subprimals were transported under refrigeration $\left(2^{\circ} \mathrm{C}\right)$ to the Colorado State University (CSU) Meat Laboratory for further processing.

\section{Muscle Fabrication}

The following five muscles were removed from each subprimal for use in this study: Adductor, Gracilis, Pectineus, Gastrocnemius - medial portion only, and Superficial digital flexor. Due to the small size of the Gastrocnemius, Pectineus, and Superficial digital flexor, muscles from both sides of the carcass were used for all muscles. Each pair of muscles was further reduced to seven $(2.54 \mathrm{~cm})$ steaks. Following fabrication, steaks assigned to the 2-day aging period were immediately cooked and prepared for WBSF testing. Sample steaks were individually vacuum packaged and randomly assigned to one of the following postmortem aging periods: $2,4,6,10,14,21$, and 28 days. Steaks remained in a fresh-chilled state $\left(2^{\circ} \mathrm{C}\right)$ until WBSF testing was performed on the designated day. 


\section{Warner-Bratzler Shear Force Determination}

Following the completion of aging, steaks were cooked to a peak internal temperature of $72^{\circ} \mathrm{C}$ in pairs on electric grills (model GGR64, Salton, Inc., Mt. Prospect, IL) that heat the steaks from both sides, simultaneously. A Type K thermocouple (Omega Engineering Inc., Stamford, CT) was placed in the geometric center of each steak, and internal temperature was monitored during cooking using a microprocessor thermometer (model HH21, Omega Engineering Inc., Stamford, CT). Peak off temperature was recorded for each steak. After cooking, each steak was allowed to equilibrate to an ambient room temperature $\left(22^{\circ} \mathrm{C}\right)$ and up to six cores (1.27 cm in diameter) were removed from each steak parallel to the muscle fiber orientation. Each core was sheared once, perpendicular to the muscle fiber orientation, using an Instron Testing Machine (model 4443, Instron, Corp., Canton, MA) fitted with a Warner-Bratlzer shear head (cross speed: $200 \mathrm{~mm} / \mathrm{min}$ ). Peak shear force measurements of cores from each steak were recorded and averaged to obtain a single shear force value for each steak.

Statistical Analysis

Analysis of Warner-Bratzler shear force was conducted using the restricted maximum likelihood estimation method (REML) in the Mixed models procedure of SAS (SAS Inst. Inc., Cary, NC). A predetermined level of significance $(P<0.05)$ was used for all comparisons. The repeated measures analysis of variance (ANOVA) model included main effects, two-way, and three-way interactions between the fixed independent effects of quality grade (grade), postmortem aging period (age), and muscle type (muscle). Random effects included carcass nested within grade, and the 
two-way interactions of muscle x carcass within grade and age x carcass within grade. Peak internal steak temperature served as a covariate for all analyses of WBSF. Degrees of freedom were estimated using the Kenward-Roger method in the Mixed models procedure. Least squares means were generated for each muscle by aging period subclass. The Superficial digital flexor muscle was excluded from the ANOVA due to the lack of homogeneity of variance and non-significance of the age effect $(P=0.475)$

\section{Exponential Decay Models}

The NLIN and NLMIXED procedures of SAS (SAS Inst. Inc., Cary, NC) were utilized to develop the exponential decay models used to create the aging curves shown in Figures 3.1 through 3.4. The non-linear mixed model (NLMIXED) allowed for a random carcass effect and was used for the Gastrocnemius, which was the only muscle to require carcass to carcass variation. The NLIN model was used for all muscles (Adductor, Gracilis, Pectineus) that did not demonstrate carcass to carcass variation. Least squares means (muscle $\times$ age) for the USDA Select Gracilis and the Adductor, Gastrocnemius, and Pectineus muscles were fitted to the following exponential decay model:

$$
W B S F=a \times \exp (-b \times(a g e-2))+a 2 \times \exp (-b 2 \times(a g e-2))
$$

The premium Choice Gracilis muscle was fitted to the following exponential decay model:

$$
W B S F=(a+d \text { Choice }) \times \exp (-b \times(\text { age }-2))+(a 2+\text { dChoice }) \times \exp (-b 2 \times(\text { age }-2))
$$

Both models represent a two-component process, in which $a$ is the height of the first component, $b$ is the slope of the first component, $a 2$ is the height of the second component, $b 2$ is the slope of the second component, and dChoice is the height 
adjustment for the premium Choice curve. The first component represents the initial, rapid decrease in toughness during postmortem storage, and the second component represents the more gradual decrease in toughness during extended postmortem aging. Due to the position of the 28 day least square mean for the Gastrocnemius muscle, the estimated exponential decay curve increased at the end of the aging curve. However, since a muscle should not become less tender during postmortem storage, the curve was adjusted to a constant value at the 22 day point. Adjusted $\mathrm{R}^{2}$ values were calculated using the least squares means and are listed in Tables 3.3 and 3.4 with the parameter estimates used in the exponential decay models. Changes in WBSF for the Superficial digital flexor (Figure 3.5) could not be represented using an exponential decay model, as no improvement in WBSF occurred during aging to 28 days postmortem.

\section{Results and Discussion}

Most studies that have estimated an overall tenderness value for the carcass have utilized the Longissimus muscle (Cross et al., 1976; Pierson and Fox, 1976; O’Connor et al., 1997), and did not obtain tenderness measurements on other muscles, especially from the chuck or round primals. Tenderness between muscles within a carcass has been shown to differ greatly (Shackelford et al., 1995; Gruber et al., 2006). Ramsbottom and Strandine (1948) reported a range from 3.22 to $7.39 \mathrm{~kg}$ (WBSF) in fifty beef muscles that had been aged five days from the chuck, rib, loin, and round. Traditionally, tenderness studies have applied a common aging period to all samples (Davis et al., 1979; Shackelford et al., 1995; Reuter et al., 2002; Von 
Seggern et al., 2005), potentially preventing certain muscles from achieving a maximum aging response.

\section{Effects of Postmortem Aging}

When Bratcher et al. (2005) analyzed the effects of postmortem aging and quality grade (USDA Select and premium USDA Choice) on nine muscles of the beef chuck and round at four postmortem aging periods (7, 14, 21, and $28 \mathrm{~d})$, an interaction was reported between quality grade and postmortem aging $(P<0.05)$, but no interaction occurred between individual muscle and postmortem aging $(P>0.05)$. Shackelford et al. $(1995)$ reported a tenderness difference $(P<0.05)$ between 10 beef muscles of the chuck, loin, and round that had been aged 14 days. In agreement with Shackelford et al. (1995), analysis of variance in the present study revealed a twoway interaction between muscle and age $(P<0.0001)$, suggesting that muscles evaluated from differing anatomical locations within the carcass in this study responded differently to postmortem aging. Shear force values decreased with increasing postmortem aging time for all muscles except for the Superficial digital flexor. This was likely due to the high amount of connective tissue present in varying densities throughout the Superficial digital flexor muscle resulting in variable and/or inaccurate measurement of WBSF. Therefore, a different cooking method, such as moist heat (i.e., braising), may have been needed to better match recommended preparation of this muscle and to solubilize the collagen. In disagreement with Gruber et al. (2006), the interactions with grade (grade $\times$ muscle $\times$ age) proved not to be statistically useful $(P=0.43)$. Smith et al. (1985) stated that the use of marbling to explain differences in shear force values of top, bottom, and eye of round steaks was 
of limited value. Muscles of the round tend to have less intramuscular fat than muscles from the chuck, rib, and loin, possibly explaining the lack of a quality grade effect found in this study. Select and premium Choice Gracilis samples did differ $(P<0.0001)$. Since quality grade effects were not evident for the Adductor, Gastrocnemius, Pectineus, and Superficial digital flexor, all results are presented for these muscles as a combination of the USDA Select and premium USDA Choice samples. Least squares means for the Adductor, Gastrocnemius, Pectineus, and Superficial digital flexor are shown in Appendix 1.1 and for both quality grades of the Gracilis in Appendix 1.2.

Daily rate of change in WBSF was calculated using the first derivative of the exponential decay models at 12 specific days during the postmortem aging period (Tables 3.5 and 3.6). Gracilis muscles representing both quality grades expressed a more rapid rate of change from 2 to 10 days postmortem than other muscles. The Pectineus had the slowest rate of change throughout the 28 day postmortem aging period.

To determine aging response, exponential decay models were used to predict the total change in shear force from 2 to 28 days postmortem (Tables 3.7 and 3.8). Aging responses were assigned using the same standards Gruber et al. (2006) established and are as follows: $\geq 2.2 \mathrm{~kg}$ (high), 2.1 to $1.8 \mathrm{~kg}$ (moderately high), 1.7 to $1.1 \mathrm{~kg}$ (moderate), 1.0 to $0.7 \mathrm{~kg}$ (moderately low), and $\leq 0.6 \mathrm{~kg}$ (low). The Gracilis exhibited a moderately high aging response for both USDA Select and premium USDA Choice samples, while the Adductor, Gastrocnemius, and Pectineus each had a moderately low aging response. These aging responses were slightly lower than 
those assigned to the round muscles (Biceps femoris, Rectus femoris, Semimembranosus, Semitendinosus, Vastus lateralis, and Vastus medialis) examined by Gruber et al. (2006); Select muscles had moderate, moderately high, and high aging responses while premium Choice muscles expressed low, moderate, and moderately high aging responses.

To examine the rate and change of postmortem tenderness for each muscle, the percentage of the aging response that was completed at each of the designated postmortem aging periods was calculated (Tables 3.7 and 3.8). The rate of tenderization differed greatly among the individual muscles. The Gastrocnemius achieved $100 \%$ of the aging response by 21 days postmortem, while the Pectineus only achieved $78.9 \%$ of the aging response by the same day. Even though the Gracilis was the only muscle to have quality grade significance $(P<0.05)$, the postmortem tenderization rate for both the Select and premium Choice samples was similar (Figure 3.3); both achieved a majority of the aging response by 23 days postmortem. The Gastrocnemius had the highest initial WBSF at day 2 of the muscles with no quality grade effect, but completed $91 \%$ of the aging response by day 14 , which is significantly higher than the Adductor and Pectineus. The Adductor and Pectineus completed $76.5 \%$ and $56.5 \%$ of the aging response, respectively, at day 14 .

Smith et al. (1978) stated that maximum tenderization (minimum shear force requirement) was achieved by 5 days for the Vastus medialis and by 8 days of postmortem aging for the Semimembranosus, Semitendinosus, Biceps femoris, Rectus femoris, and Vastus lateralis muscles of the round. Gruber et al. (2006) recommended that USDA Select Biceps femoris, Rectus femoris, Semimembranosus, 
Semitendinosus, Vastus lateralis, and Vastus medialis muscles be aged between 20 and 26 days, and the same premium USDA Choice muscles be aged between 6 and 21 days. The length of time necessary for each muscle in the present study to achieve the majority of the aging response is provided in Tables 3.9 and 3.10. The percentages necessary for the majority of the aging response to be completed also were adopted from the Gruber et al. (2006) study. Aging times for muscles with aging responses $\geq$ $2.2 \mathrm{~kg}$ (high), 2.1 to $1.8 \mathrm{~kg}$ (moderately high), 1.7 to $1.1 \mathrm{~kg}$ (moderate), 1.0 to $0.7 \mathrm{~kg}$ (moderately low), and $\leq 0.6 \mathrm{~kg}$ (low) corresponded to the day that at least 96\%, 95\%, $94 \%, 90 \%$, and $85 \%$ of the aging response was completed, respectively. All muscles except the Superficial digital flexor required at least a 14 day postmortem aging period, with most falling between 20 and 25 days. The Pectineus had the lowest 2 and 28 day WBSF, but required the longest time, 25 days, to complete the majority of its aging response. A ranking of WBSF values for all muscles at four postmortem aging periods is presented in Table 3.11. The Pectineus was the most tender muscle and the Superficial digital flexor was the toughest muscle throughout the 28 day aging period. Individual Muscle Tenderness

Senaratne et al. (2010) aged USDA Choice Pectineus, Sartorius, Gracilis, Vastus medialis, and Vastus lateralis muscles for 14 days and reported WBSF values of 3.76 and $4.78 \mathrm{~kg}$ for the Pectineus and Gracilis muscles, respectively. Following 5 days of postmortem aging, Ramsbottom and Strandine (1948) reported WBSF values of 4.81, 4.31, 5.21, 3.67, and $4.53 \mathrm{~kg}$ for the Adductor, Gastrocnemius, Gracilis, Pectineus, and Superficial digital flexor, respectively. Reuter et al. (2002) analyzed the uniformity of WBSF shear force values in different locations of four round 
muscles with a postmortem aging time of 10 days. The Adductor was relatively uniform in shear force, regardless of coring location, and averaged $4.16 \mathrm{~kg}$. When comparing the aforementioned WBSF shear force data to the values achieved in this study at approximately the same aging time, the shear force values in the literature were higher for the Adductor and Pectineus, nearly identical for the Gastrocnemius, mid-range (higher and lower) for the Gracilis, and much lower for the Superficial digital flexor.

Individual muscle tenderness varied greatly in the present study, with a range of $48.56 \mathrm{~kg}$ in premium Choice samples, and a range of $30.83 \mathrm{~kg}$ in Select samples. The reason for this substantial variation was due to the extremely high WBSF of the Superficial digital flexor (average WBSF $=11.11 \mathrm{~kg}$ ). Excluding the Superficial digital flexor, the range of the remaining muscles was 7.61 and $6.57 \mathrm{~kg}$ for Select and premium Choice, respectively. Due to the varying densities of connective tissue in the Superficial digital flexor, average WBSF values for this muscle had a range of 28.95 and $47.01 \mathrm{~kg}$ for Select and premium Choice samples, respectively. Cores removed only from muscle tissue, avoiding large pieces of connective tissue, within the Superficial digital flexor were very tender, with the lowest WBSF being $2.83 \mathrm{~kg}$. However, due to the highly interspersed connective tissue and small diameter of the muscle, cores could not always be excised from muscle exclusively.

Variation among WBSF values obtained from different institutions has been shown to occur (Wheeler et al., 1997a; 1997b), due to differences in procedures regarding initial internal temperature immediately prior to cooking, peak internal temperature obtained, meat temperature at coring, and use of different testing 
instruments. Additionally, most tenderness research had performed shear force testing after the meat product had been frozen and thawed (Davis et al., 1979; Shanks et al., 2002), and freezing has been shown to decrease shear values (Shanks et al., 2002). Many early studies (Ramsbottom and Strandine, 1948; Smith et al., 1978) also cooked the samples to a higher peak internal temperature, $75^{\circ} \mathrm{C}$ and $76.7^{\circ} \pm 2^{\circ} \mathrm{C}$, respectively, than the end point temperature used in this study. Higher peak internal temperatures have been shown to increase shear force values (Wheeler et al., 1994), and this, combined with institution and cooking method variation, likely explains the disparity between the studies.

\section{Implications}

Individual muscle and postmortem aging time affected beef tenderness. With the addition of this round aging information to the NCBA Industry Guide for Beef Aging, packers, branded beef programs, retailers, and foodservice operations will be able to better manage postmortem aging practices to increase beef eating satisfaction and value. This illustrates the potential for these round muscles to be sold in foodservice operations and retail stores with marketing emphasis being placed on the acceptable tenderness of these cuts. 
Table 3.1. Simple means and standard deviations for carcass traits of the experimental sample stratified by quality grade

\begin{tabular}{lccccccc}
\hline \hline & \multicolumn{3}{c}{ USDA Select } & & \multicolumn{3}{c}{ Premium USDA Choice } \\
\cline { 2 - 4 } \cline { 6 - 8 } Trait & $\mathrm{n}$ & Mean & SD & & $\mathrm{n}$ & Mean & SD \\
\hline Carcass weight, $\mathrm{kg}$ & 40 & 367 & 93.87 & & 40 & 381 & 79.51 \\
Adjusted fat thickness, cm & 40 & 1.2 & 0.12 & & 40 & 1.5 & 0.12 \\
Ribeye area, cm ${ }^{2}$ & 40 & 90.8 & 1.90 & & 40 & 89.2 & 1.10 \\
Kidney, pelvic, and heart fat, \% & 40 & 2.2 & 0.30 & & 40 & 2.2 & 0.27 \\
Calculated USDA yield grade & 40 & 2.7 & 0.67 & & 40 & 3.2 & 0.45 \\
Marbling score $^{\mathrm{a}}$ & 40 & 343 & 23.69 & & 40 & 570 & 47.30 \\
\hline a 300 to 399 = Slight, 400 to 499 = Small, 500 to 599 = Modest, 600 to 699 = Moderate.
\end{tabular}


Table 3.2. Individual beef muscles removed from a carcass, the number of each muscle evaluated, and the subprimal from which each muscle was removed

\begin{tabular}{lccc}
\hline \hline Muscle & $\mathrm{n}$ & Subprimal & IMPS $^{\mathrm{a}}$ \\
\hline Adductor & 160 & Inside round & 168 \\
Gastrocnemius - medial portion & 160 & Bottom round & $171 \mathrm{~F}$ \\
Gracilis & 160 & Inside round & 168 \\
Pectineus & 160 & Inside round & 168 \\
Superficial digital flexor & 160 & Bottom round & $171 \mathrm{~F}$ \\
\hline
\end{tabular}

${ }^{\mathrm{a}}$ IMPS = Institutional Meat Purchase Specifications (USDA, 1996). 
Table 3.3. Coefficients of determination $\left(\mathrm{R}^{2}\right)$ and parameter estimates for models fitted to four beef muscles

\begin{tabular}{|c|c|c|c|c|c|}
\hline \multirow[b]{2}{*}{ Muscle } & \multirow[b]{2}{*}{$\mathrm{R}^{2 \mathrm{a}}$} & \multicolumn{4}{|c|}{ Parameter estimate $^{\mathrm{b}}$} \\
\hline & & $\mathrm{a}$ & b & $a^{2}$ & $b^{2}$ \\
\hline Adductor & 0.96 & 0.7652 & 0.1489 & 3.7350 & 0.0023 \\
\hline Gastrocnemius & 0.96 & 2.1004 & 0.0790 & 2.5312 & -0.0104 \\
\hline Pectineus & 0.98 & 3.6291 & 0.0089 & 0.1288 & 0.7064 \\
\hline Superficial digital flexor ${ }^{c}$ & - & - & - & - & - \\
\hline
\end{tabular}

${ }^{\mathrm{a}}$ Adjusted $\mathrm{R}^{2}$ values computed using the least squares means.

${ }^{\mathrm{b}}$ Parameter estimates correspond to the following exponential decay model: $W B S F=a \times$ $\exp (-b(a g e-2))+a 2 \times \exp (-b 2(a g e-2))$.

${ }^{\mathrm{c}}$ Warner-Bratzler shear force of Superficial digital flexor could not be fitted to exponential decay model; no improvement in WBSF occurred with aging to $28 \mathrm{~d}$. 
Table 3.4. Coefficients of determination $\left(\mathrm{R}^{2}\right)$ and parameter estimates for models fitted to USDA Select and premium USDA Choice Gracilis

\begin{tabular}{lcccccc}
\hline \hline & & \multicolumn{5}{c}{ Parameter estimate $^{\mathrm{b}}$} \\
\cline { 3 - 7 } Quality grade & $\mathrm{R}^{2 \mathrm{a}}$ & $\mathrm{a}$ & $\mathrm{b}$ & $\mathrm{a}^{2}$ & $\mathrm{~b}^{2}$ & dChoice \\
\hline USDA Select & 1.00 & 2.0923 & 0.1220 & 4.2125 & 0.0006 & - \\
$\begin{array}{l}\text { Premium USDA } \\
\text { Choice }^{\mathrm{c}}\end{array}$ & 0.96 & 2.0923 & 0.1220 & 4.2125 & 0.0006 & -0.2965 \\
\hline
\end{tabular}

${ }^{\mathrm{a}}$ Adjusted $\mathrm{R}^{2}$ values computed using the least squares means.

${ }^{\mathrm{b}}$ Parameter estimates correspond to the following exponential decay model for USDA Select: $W B S F=a \times \exp (-b(a g e-2))+a 2 \times \exp (-b 2(a g e-2))$.

${ }^{c}$ Parameter estimates correspond to the following exponential decay model for upper $2 / 3$ USDA Choice: $W B S F=(a+$ dChoice $) \times \exp (-b \times($ age -2$))+(a 2+$ dChoice $) \times$ $\exp (-b 2 \times(a g e-2))$. 
Table 3.5. Rate of change in Warner-Bratzler shear force $(\mathrm{kg})$ at twelve postmortem aging periods (d) as estimated by exponential decay models ${ }^{\mathrm{a}}$ fitted to four beef muscles

\begin{tabular}{|c|c|c|c|c|c|c|c|c|c|c|c|c|}
\hline \multirow[b]{2}{*}{ Muscle } & \multicolumn{12}{|c|}{ Days postmortem (kg, WBSF/d) } \\
\hline & 2 & 3 & 4 & 5 & 6 & 7 & 8 & 9 & 10 & 14 & 21 & 28 \\
\hline Adductor & -0.12 & -0.11 & -0.09 & -0.08 & -0.07 & -0.06 & -0.06 & -0.05 & -0.04 & -0.03 & -0.01 & -0.01 \\
\hline Gastrocnemius & -0.14 & -0.13 & -0.11 & -0.10 & -0.09 & -0.08 & -0.08 & -0.07 & -0.06 & -0.03 & 0.00 & 0.00 \\
\hline Pectineus & -0.12 & -0.08 & -0.05 & -0.04 & -0.04 & -0.03 & -0.03 & -0.03 & -0.03 & -0.03 & -0.03 & -0.03 \\
\hline $\begin{array}{l}\text { Superficial digital } \\
\text { flexor }\end{array}$ & - & - & - & - & - & - & - & - & - & - & - & - \\
\hline
\end{tabular}

${ }^{\mathrm{a}}$ Exponential decay model: $W B S F=a \times \exp (-b(a g e-2))+a 2 \times \exp (-b 2(a g e-2))$.

Rate of change estimated by first derivative: $-b \times a \times \exp (-b \times(a g e-2))+-b 2 \times a 2 \times \exp (-b 2 \times(a g e-2))$.

${ }^{\mathrm{b}}$ Warner-Bratzler shear force of Superficial digital flexor could not be fitted to exponential decay model; no improvement in WBSF occurred with aging to $28 \mathrm{~d}$. 
Table 3.6. Rate of change in Warner-Bratzler shear force $(\mathrm{kg})$ at twelve postmortem aging periods (d) as estimated by exponential decay models fitted to USDA Select and Premium USDA Choice Gracilis

\begin{tabular}{lcccccccccccc} 
& \multicolumn{10}{c}{ Days postmortem $(\mathrm{kg}, \mathrm{WBSF} / \mathrm{d})$} \\
\cline { 2 - 13 } & 2 & 3 & 4 & 5 & 6 & 7 & 8 & 9 & 10 & 14 & 21 & 28 \\
\hline Quality grade $_{\text {USDA Select }}^{\mathrm{a}}$ & -0.26 & -0.23 & -0.20 & -0.18 & -0.16 & -0.14 & -0.13 & -0.11 & -0.10 & -0.06 & -0.03 & -0.01 \\
Premium USDA & -0.22 & -0.20 & -0.17 & -0.15 & -0.14 & -0.12 & -0.11 & -0.10 & -0.08 & 0.00 & -0.02 & -0.01 \\
Choice $^{\mathrm{b}}$ & & & & & & & & & & & &
\end{tabular}

${ }^{\mathrm{a}}$ Exponential decay model for USDA Select: $W B S F=a \times \exp (-b(a g e-2))+a 2 \times \exp (-b 2(a g e-2))$.

Rate of change estimated by first derivative: $-b \times a \times \exp (-b \times(a g e-2))+-b 2 \times a 2 \times \exp (-b 2 \times(a g e-2))$.

${ }^{\mathrm{b}}$ Exponential decay model for premium USDA Choice: $W B S F=(a+d$ Choice $) \times \exp (-b \times(a g e-2))+(a 2+d$ Choice $) \times \exp (-b 2 \times$ $(a g e-2))$. Rate of change estimated by first derivative: $(-b \times(a-d$ Choice $) \times \exp (-b($ age -2$))+(-b 2 \times(a 2-d C h o i c e) \times \exp (-b 2(a g e-$ 2)). 
Table 3.7. Warner-Bratzler shear force (WBSF) of four beef muscles at $2 \mathrm{~d}$ postmortem (kg), the change in shear force through $28 \mathrm{~d}$ postmortem (aging response), and the percentage (\%) of that change completed at each of six postmortem aging periods

\begin{tabular}{|c|c|c|c|c|c|c|c|c|}
\hline \multirow[b]{2}{*}{ Muscle } & \multirow{2}{*}{$\begin{array}{c}2-d \\
\text { WBSF }^{a}\end{array}$} & \multirow{2}{*}{$\begin{array}{l}\text { Aging response } \\
(\mathrm{kg})^{\mathrm{b}}\end{array}$} & \multicolumn{6}{|c|}{ Days postmortem } \\
\hline & & & 4 & 6 & 10 & 14 & 21 & 28 \\
\hline Adductor & 4.50 & 1.0 & 22.2 & 39.1 & 62.3 & 76.5 & 91.1 & 100.0 \\
\hline Gastrocnemius & 4.63 & 1.0 & 24.3 & 44.3 & 73.3 & 91.0 & 100.0 & 100.0 \\
\hline Pectineus & 3.76 & 0.9 & 18.4 & 28.3 & 43.0 & 56.5 & 78.9 & 100.0 \\
\hline Superficial digital flexor ${ }^{\mathrm{C}}$ & - & - & - & - & - & - & - & - \\
\hline
\end{tabular}

${ }^{\mathrm{a}}$ WBSF at two days postmortem predicted by exponential decay model.

${ }^{\mathrm{b}}$ Aging response equal to predicted 2-d WBSF minus predicted 28-d WBSF.

${ }^{\mathrm{c}}$ Warner-Bratzler shear force of Superficial digital flexor could not be fitted to exponential decay model; no improvement in WBSF occurred with aging to $28 \mathrm{~d}$. 
Table 3.8. Warner-Bratzler shear force (WBSF) of Gracilis at $2 \mathrm{~d}$ postmortem (kg), the change in shear force through $28 \mathrm{~d}$ postmortem (aging response), and the percentage (\%) of that change completed at each of six postmortem aging periods

Days postmortem

\begin{tabular}{lcccccccc} 
& 2-d & Aging response & & & & & \\
\cline { 3 - 8 } Quality grade & WBSF $^{\mathrm{a}}$ & $(\mathrm{kg})^{\mathrm{b}}$ & 4 & 6 & 10 & 14 & 21 & 28 \\
\hline USDA Select & 6.30 & 2.1 & 22.2 & 39.6 & 64.0 & 79.2 & 93.5 & 100.0 \\
Premium USDA Choice & 5.71 & 1.8 & 22.1 & 39.5 & 64.0 & 79.2 & 93.4 & 100.0 \\
\hline
\end{tabular}

${ }^{\mathrm{a}}$ WBSF at two days postmortem predicted by exponential decay model.

${ }^{\mathrm{b}}$ Aging response equal to predicted 2-d WBSF minus predicted 28-d WBSF. 
Table 3.9. Change in shear force from 2 through $28 \mathrm{~d}$ postmortem (aging response, kg) and the length of postmortem aging (d) needed for a majority of this change to occur for four beef muscles

\begin{tabular}{lcc}
\hline \hline Muscle & Aging response & Aging time $^{\mathrm{a}}$ \\
\hline Adductor & 1.0 & 21 \\
Gastrocnemius & 1.0 & 14 \\
Pectineus & 0.9 & 25 \\
Superficial digital flexor & - & - \\
\hline${ }^{\mathrm{a}}$ Aging times for muscles with aging responses $\geq 2.2 \mathrm{~kg}$ (high), 2.1 to $1.8 \mathrm{~kg}$ (moderately \\
high), 1.7 to $1.1 \mathrm{~kg}$ (moderate), 1.0 to $0.7 \mathrm{~kg}$ (moderately low), and $\leq 0.6 \mathrm{~kg}$ (low) \\
correspond to the day that at least 96\%, 95\%, 94\%, 90\% and 85\% of the aging response \\
was completed, respectively. \\
b Warner-Bratzler shear force of Superficial digital flexor did not decrease with \\
increasing time of postmortem storage.
\end{tabular}


Table 3.10. Change in shear force from 2 through $28 \mathrm{~d}$ postmortem (aging response, $\mathrm{kg}$ ) and the length of postmortem aging (d) needed for a majority of this change to occur for USDA Select and premium USDA Choice Gracilis

\begin{tabular}{lcc}
\hline \hline Quality grade & Aging response & Aging time $^{\mathrm{a}}$ \\
\hline USDA Select & 2.1 & 23 \\
Premium USDA Choice & 1.8 & 23 \\
\hline${ }^{a}$ Aging times for muscles with aging responses $\geq 2.2 \mathrm{~kg}$ (high), 2.1 to $1.8 \mathrm{~kg}$ (moderately \\
high), 1.7 to $1.1 \mathrm{~kg}$ (moderate), 1.0 to $0.7 \mathrm{~kg}$ (moderately low), and $\leq 0.6 \mathrm{~kg}$ (low) \\
correspond to the day that at least $96 \%, 95 \%, 94 \%, 90 \%$ and $85 \%$ of the aging response \\
was completed, respectively.
\end{tabular}


Table 3.11. Rank of five beef muscles from lowest Warner-Bratzler shear force (WBSF) to highest WBSF at four postmortem aging periods $^{\mathrm{a}}$

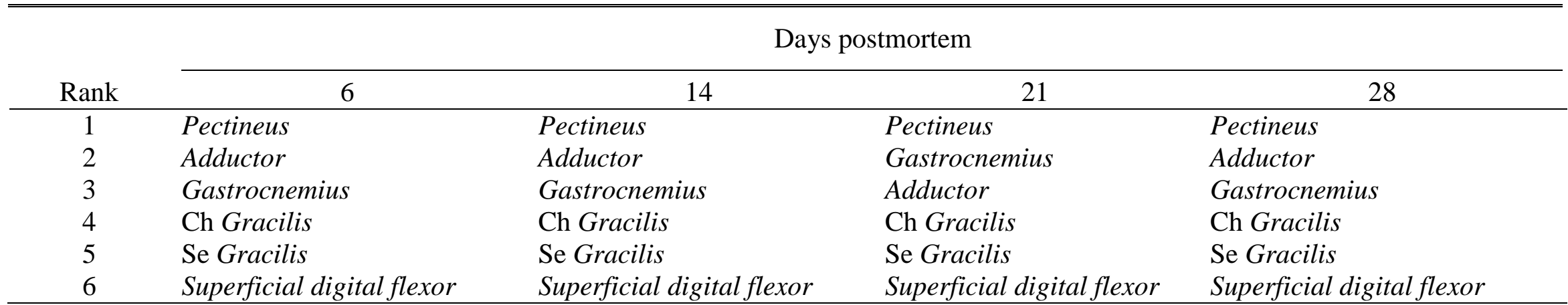

${ }^{\mathrm{a}}$ Quality grade was not significant for the Adductor, Gastrocnemius, Pectineus, and Superficial digital flexor, so no distinction was made. 


\section{Adductor}

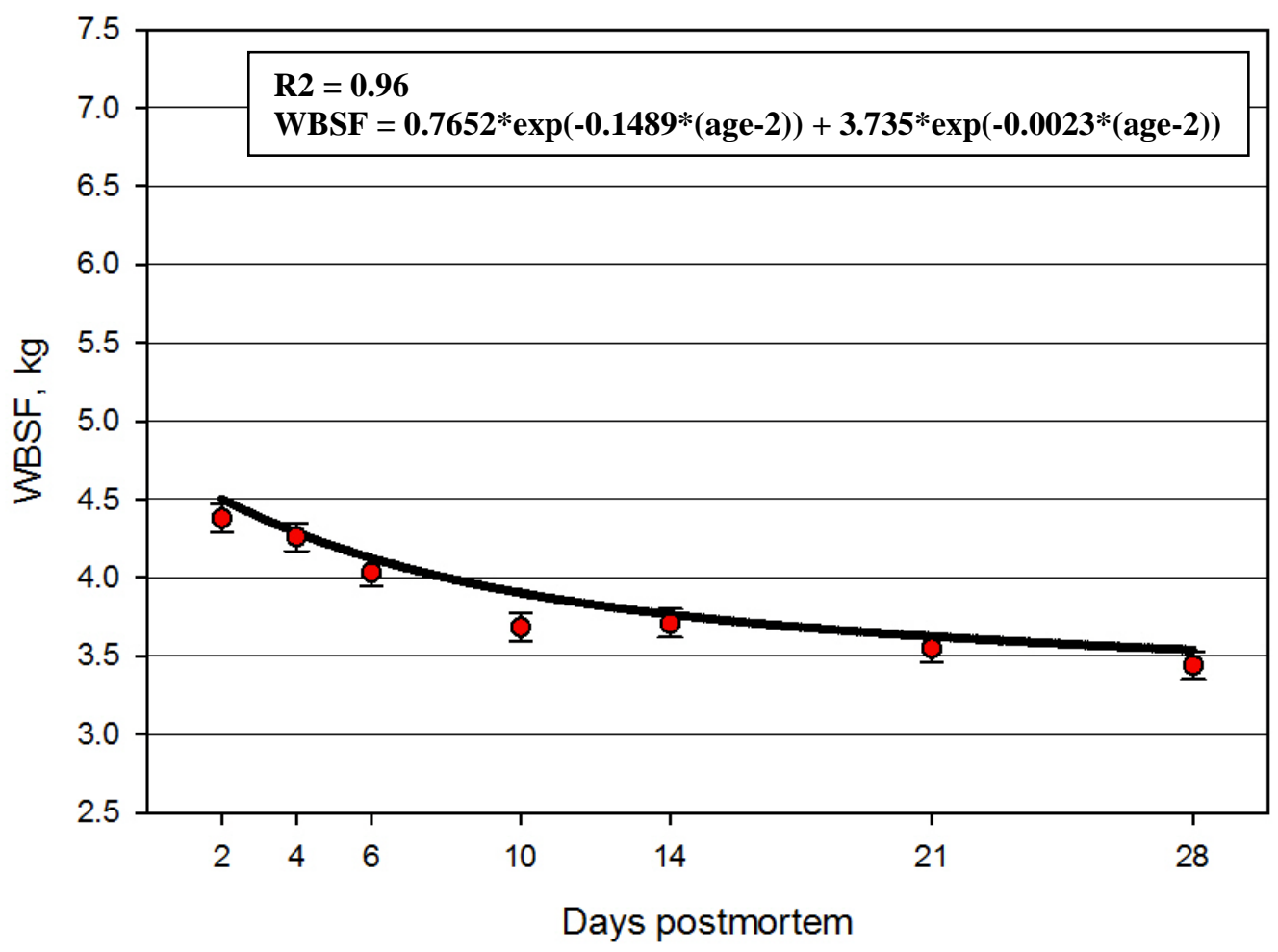

Figure 3.1. Least squares means \pm standard errors for Warner-Bratzler shear force (WBSF) of Adductor at seven postmortem aging points. Grade was not significant for the Adductor, so no distinction was made. The variable "age" is the number of days postmortem. The $\mathrm{R}^{2}$ is the maximum proportion of total variability explained by the least squares means. The constant "exp” equals the base of the natural logarithm (2.71828). 


\section{Gastrocnemius}

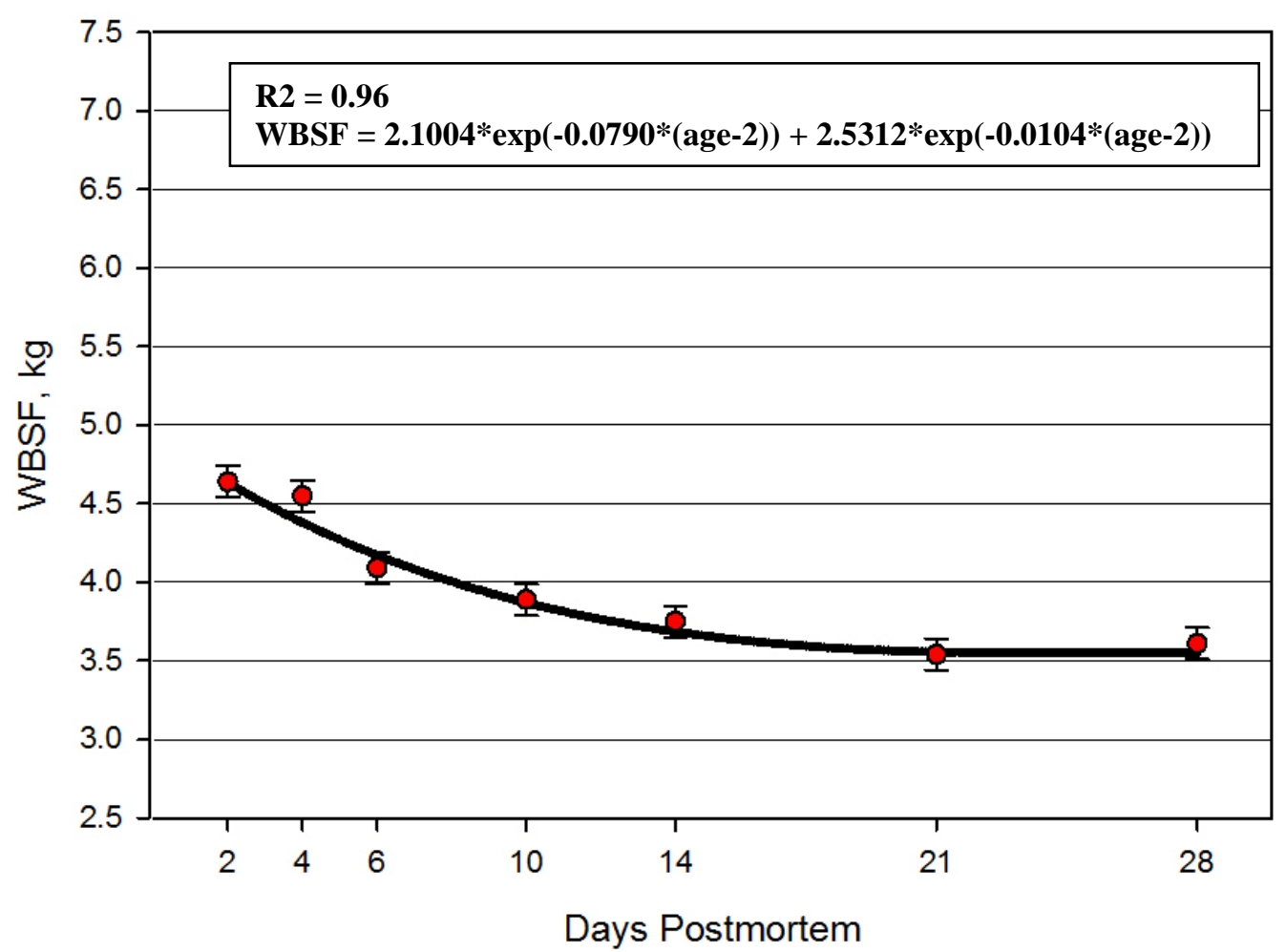

Figure 3.2. Least squares means \pm standard errors for Warner-Bratzler shear force (WBSF) of Gastrocnemius at seven postmortem aging points. Grade was not significant for the Gastrocnemius, so no distinction was made. The variable "age" is the number of days postmortem. The $\mathrm{R}^{2}$ is the maximum proportion of total variability explained by the least squares means. The constant "exp" equals the base of the natural logarithm (2.71828). 


\section{Gracilis}

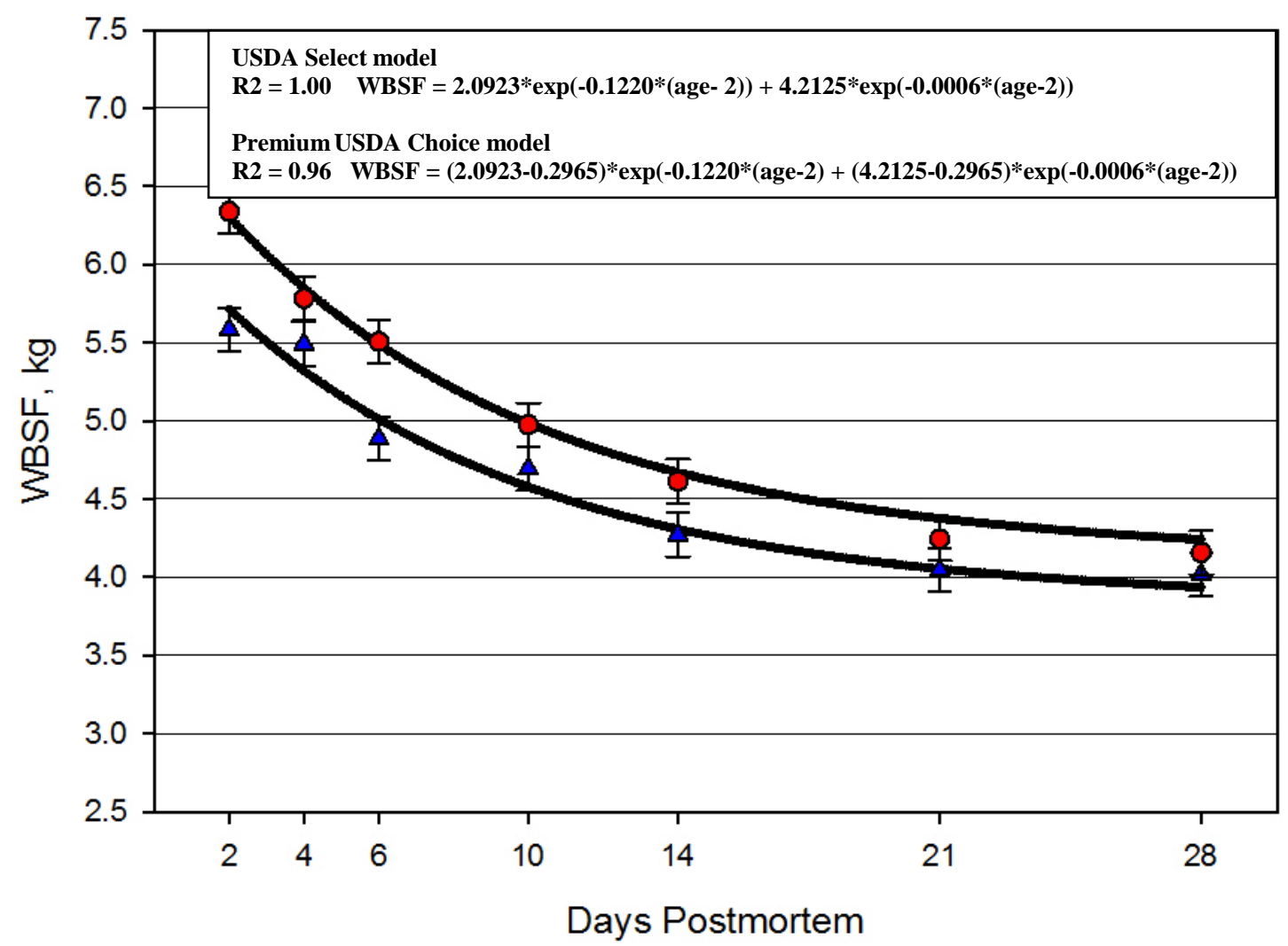

$\Delta$ USDA Select - Premium USDA Choice

Figure 3.3. Least squares means \pm standard errors for Warner-Bratzler shear force (WBSF) of Gracilis at seven postmortem aging points. The variable "age" is the number of days postmortem. The $\mathrm{R}^{2}$ is the maximum proportion of total variability explained by the least squares means. The constant "exp" equals the base of the natural logarithm (2.71828). 


\section{Pectineus}

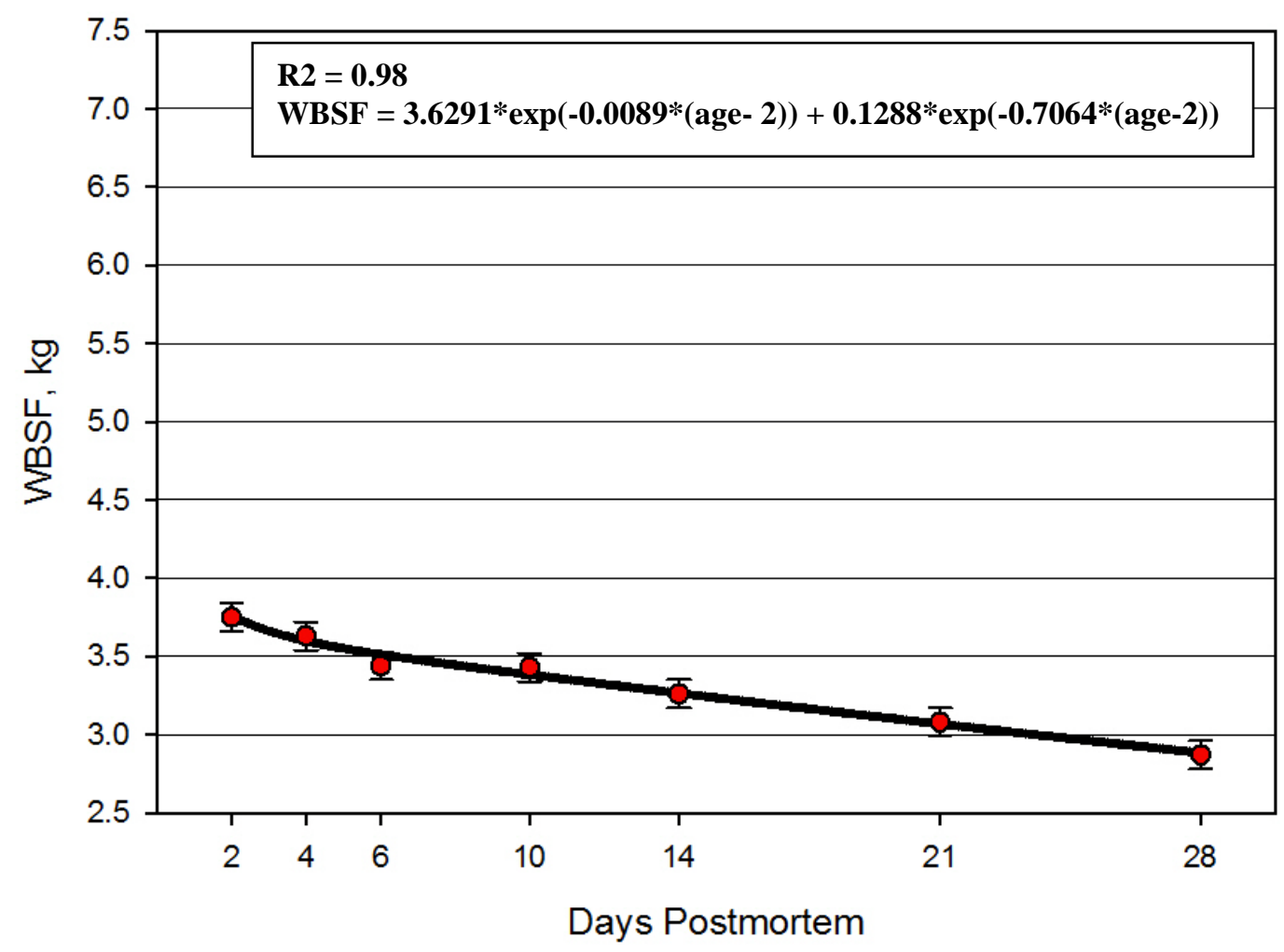

Figure 3.4. Least squares means \pm standard errors for Warner-Bratzler shear force (WBSF) of Pectineus at seven postmortem aging points. Grade was not significant for the Pectineus, so no distinction was made. The variable "age" is the number of days postmortem. The $\mathrm{R}^{2}$ is the maximum proportion of total variability explained by the least squares means. The constant “exp” equals the base of the natural logarithm (2.71828). 


\section{Superficial digital flexor}

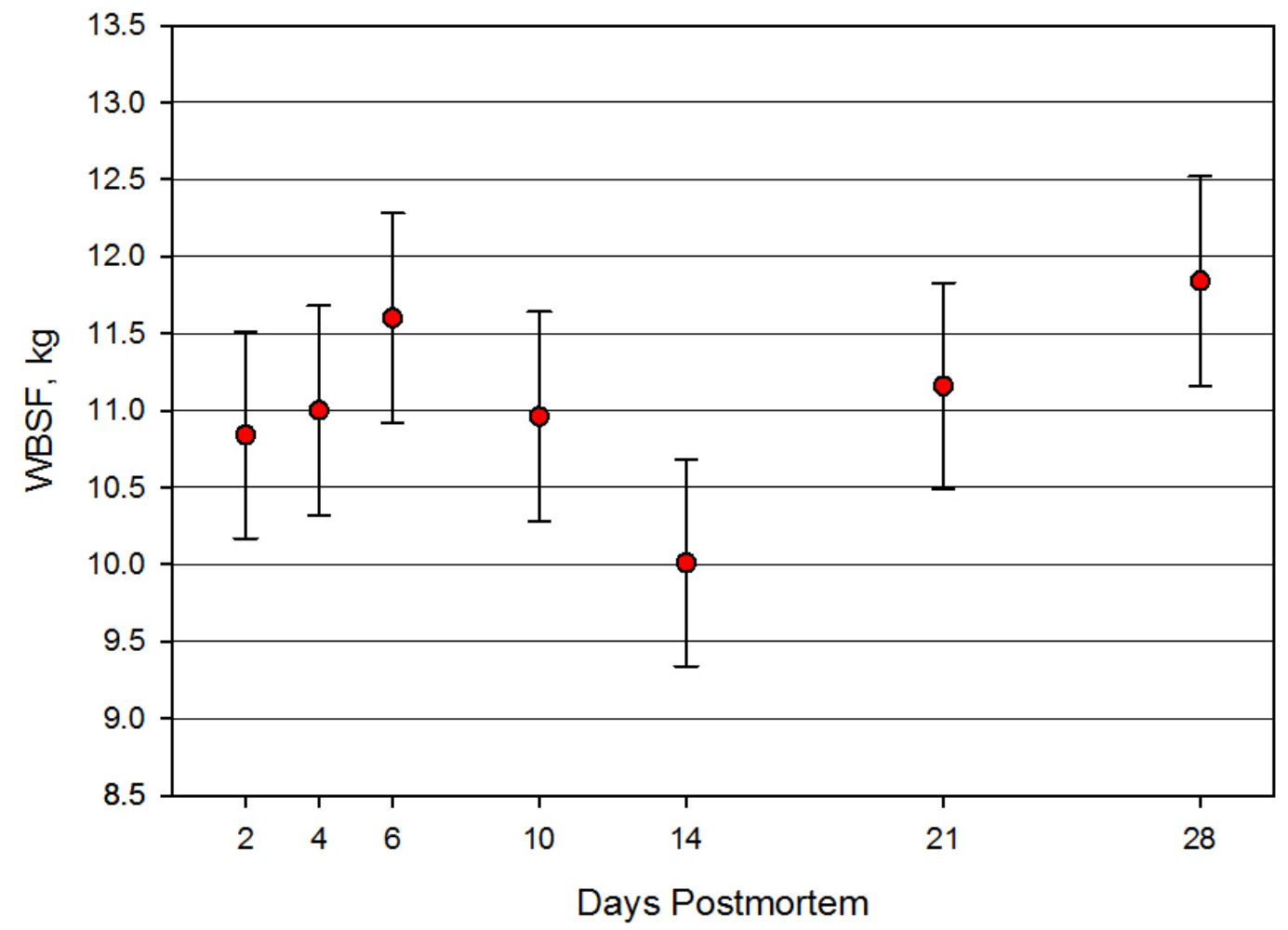

Figure 3.5. Least squares means \pm standard errors for Warner-Bratzler shear force (WBSF) of Superficial digital flexor at seven postmortem aging points. Grade was not significant for the Superificial digital flexor, so no distinction was made. Warner-Bratzler shear force of Superficial digital flexor could not be fitted to exponential decay model; no improvement in WBSF occurred with aging to $28 \mathrm{~d}$. 


\title{
CHAPTER IV
}

\section{MUSCLES OF THE ROUND: NUTRIENT COMPOSITION OF CUTS}

\begin{abstract}
The objective of this study was to determine the nutrient composition of six muscles of the round, including five of the new Innovative Beef Value Cuts marketed by the National Cattlemen's Beef Association (NCBA). Ten USDA Select and 10 premium USDA Choice beef carcasses were selected from a commercial beef packing plant in Colorado. The bottom (Gooseneck) and inside rounds were collected from one side of the carcass for further fabrication into the following muscles: Adductor, Gastrocnemius, Gracilis, Pectineus, Semimembranosus, and Superficial digital flexor. Semimembranosus samples also were collected from these carcasses, but individual muscle quality grade data was not maintained. The Adductor, Gracilis, Pectineus, Semimembranosus, and Superficial digital flexor were analyzed for dry matter, moisture, crude protein, and ash percentages. All muscles were evaluated for lipid percentage and fatty acid and cholesterol composition. All analyses were completed on raw muscle only (i.e., not cooked). The Adductor, Gastrocnemius, Gracilis, and Pectineus muscles meet the USDA requirements to be labeled as “extra lean,” and the Superficial digital flexor muscle meets the requirements to be labeled as "lean," in regard to the total fat, saturated fat, and
\end{abstract}


cholesterol content in each muscle. This illustrates the potential for these round muscles to be sold in foodservice operations and retail stores with marketing emphasis being placed on the exceptional leanness of these cuts. 


\section{Materials and Methods}

Product Selection

USDA Select $(n=10)$ and premium USDA Choice $(n=10)$ beef carcasses were selected at a beef packing plant in northeastern Colorado (Table 4.1). At two days postmortem, carcasses were individually identified and followed through fabrication to obtain the inside round (IMPS 168) and bottom (Gooseneck) round (IMPS 171F) from one side of each carcass (Table 4.2) (USDA, 1996). The subprimals were transported under refrigeration to the Colorado State University (CSU) Meat Laboratory for further processing.

\section{Muscle Fabrication and Homogenization}

The following six muscles were removed from subprimals for use in this study: Adductor, Gracilis, Pectineus, Gastrocnemius - medial portion only, Semimembranosus, and Superficial digital flexor. Samples were aged between 3 and 10 days postmortem. Individual muscle quality grade data was not maintained for the Semimembranosus, so all data reported for this muscle is presented averaging over quality grades. Individual muscles were denuded and cut into $2.54 \mathrm{~cm}$ cubes, vacuum packaged separately by muscle, and frozen $\left(-20^{\circ} \mathrm{C}\right)$. The frozen cubes were submersed in liquid nitrogen and homogenized using a commercial food processor (Blixer 4V, Robot Coupe USE, Inc., Ridgeland, MS) until the contents became a fine powder. Homogenized samples were placed into a Whirl-Pak bag (Nasco, Ft. Atkinson, WI), labeled, and stored at $-80^{\circ} \mathrm{C}$ until further analysis. 


\section{Ash Analysis}

Ash was determined in accordance with the oven method described in AOAC (1995). Approximately 1 gram of sample was placed into a dry, pre-weighted crucible and placed into an acid bath for 24 hours. Upon removal from the acid bath, the crucibles were rinsed with deionized water and placed into a $100^{\circ} \mathrm{C}$ forced drying oven for 24 hours, and then into a desiccator for 12 hours. Crucibles were placed into a Thermolyne box furnace at $600^{\circ} \mathrm{C}$ and burned for 12 hours. The crucibles were allowed to cool in a desiccator before being weighed. Ash was calculated as the remainder by weight. Dry Matter and Moisture Analysis

Dry matter and moisture was determined by following AOAC (1995). Samples were placed into a drying oven at 100 to $105^{\circ} \mathrm{C}$ for at least 16 hours and then placed into a desiccator to cool. Sample pans were removed from the desiccator and total weight was recorded (dry sample + pan). Loss in weight was reported as percent moisture.

\section{Lipid and Fatty Acid Analysis}

Total lipid was extracted from 1 gram of homogenized sample using the method of Folch et al. (1957) as modified by Bligh and Dyer (1959). Saponification and methylation was accomplished by the method of Park and Goins (1994). Fatty acid methyl esters (FAME) were analyzed via gas chromatography using a Hewlett Packard (Avondale, PA) Model 6890 series II gas chromatograph fixed with a series 7683 injector and flame ionization detector. The instrument was equipped with a 100m x 0.25-mm (id) fused silica capillary column (SP-2560 Supelco Inc. Bellefonte, 
PA). Helium was used as the carrier gas (flow rate $=1.0 \mathrm{~mL} / \mathrm{min}$ ). Column oven temperature was increased from 150 to $160^{\circ} \mathrm{C}$ and $1^{\circ} \mathrm{C}$ per minute, from 160 to $167^{\circ} \mathrm{C}$ and $0.2^{\circ} \mathrm{C}$ per minute, from 167 to $225^{\circ} \mathrm{C}$ and $1.5^{\circ} \mathrm{C}$ per minute, and then held at $225^{\circ} \mathrm{C}$ for 16 minutes. The injector and detector were maintained at $250^{\circ} \mathrm{C}$. Total run time was 100 minutes. Individual FAME were quantified as a percentage of total FAME analyzed, and identified based on authentic standards. Fatty acids were quantified by incorporating internal standards (C12:0 and C27:0) into each sample prior to methylation.

Protein Analysis

Crude protein was determined using the CSU Animal Sciences Ruminant Nutrition Lab Standard Operating Procedure for TruSpec CN Instrumentation (LECO Corp., St. Joseph, MI). A standard of EDTA (9.75\% nitrogen) and blank was run after every 25 samples. Samples were weighed (approximately 0.1 grams) into aluminum combustion tins and the weight for each was recorded. After optimizing each sample based on the standard, crude protein level was determined by multiplying each protein level by a nitrogen factor of $6.25 \%$.

\section{Cholesterol Analysis}

Cholesterol was determined by AOAC (2000) methods. Four milliliters of absolute ethanol was added to each sample and vortexed for 15 seconds. Samples were placed into a water bath $\left(80^{\circ} \mathrm{C}\right)$ for 30 minutes and then vortexed again. Ultrapure water was added to each vial, vortexed, and allowed to sit for one hour. The top layer was removed after one hour and placed into a gas chromatography (GC) vial for analysis. 


\section{Statistical Analysis}

The Mixed models procedure of SAS (SAS Inst., Inc., Cary, NC) was used to determine nutrient components and test for differences among the two quality grade classes. Type I error was set at $\alpha=0.05$ for all analyses. Fatty acid data is presented in the following two forms: normalized weight percentage of fatty acid and weight percentage of fatty acid, $\mathrm{g} / 100 \mathrm{~g}$ of total fat extracted. The normalized weight percentage of fatty acid is reported for use as a reference in comparison with scientific literature. The weight percentage of fatty acid, g/100g of total fat extracted is a value derived from the division of the normalized weight percentage by the total fat extracted from the sample. This form of data is used by USDA in the National Nutrient Database for Standard Reference (SR) and to determine if a meat product meets “extra lean” or “lean” guidelines based on saturated fat, total fat, and cholesterol content per serving (100g).

\section{Results and Discussion}

Various factors influence the nutrient composition of beef, including animal diet, time on feed (Duckett et al., 1993; French et al., 2000; Leheska et al., 2008), location and function of the muscle within the carcass (McKeith et al., 1985;

Wahrmund-Wyle et al., 2000), and quality grade of the carcass (Wahrmund-Wyle et al., 2000). Within all analyses (proximate, cholesterol, and fatty acid), differences were detected among individual muscles from differing carcass anatomic locations ( $P<0.05)$. Wahrmund-Wyle et al. (2000) found a quality grade effect $(P<0.05)$ on mean lipid and moisture concentration in 13 USDA Select and premium Choice beef 
cuts, but no difference between quality grades $(\mathrm{P}>0.05)$ in mean protein and ash concentration. For the present study, means, standard errors, and p-values of raw proximate, cholesterol, and fatty acid analyses for Select and premium Choice muscles are presented in Table 4.3, and means and standard errors for pooled quality grade data are found in Table 4.4. In agreement with Wahrmund-Wyle et al. (2000), quality grades differed in mean moisture $(P=0.02)$ and lipid $(P=0.0003)$ percentages in the present study. There was no effect of quality grade difference on mean ash $(P=0.5)$, protein $(P=0.5)$, or cholesterol $(P=0.65)$ content of the muscles in the present study. Two fatty acids were significant for a quality grade effect, C17:1 $(P=0.002)$ and $\mathrm{C} 18: 0(P=0.01)$. Analyses with a significant quality grade effect are listed in Table 4.5.

Both grades of the Superficial digital flexor and Semimembranosus muscles contained the lowest percent moisture. The Gracilis muscle contained the highest percentage of moisture, independent of quality grade. USDA Select samples averaged approximately $1 \%$ less in lipid content than premium USDA Choice muscles. The Superficial digital flexor contained the highest lipid percentage, averaging approximately 3\% more fat than the remaining muscles, independent of quality grade. The Gastrocnemius and Pectineus muscles had the lowest lipid percentages of 2.34 and $2.38 \%$, respectively. The percentages of ash were highest $(P<0.05)$ in the Adductor and lowest in the Superficial digital flexor. Percent protein values were statistically different among the individual round muscles $(P<0.05)$, with the Gracilis and Superficial digital flexor possessing the lowest protein content. 
Wahrmund-Wyle et al. (2000) assessed the nutrient composition of 13 retail cuts from the chuck, rib, loin, and round of 20 USDA Select and Choice carcasses. Proximate nutrient composition in this study was in agreement with those reported for the round muscles evaluated by Wahrmund-Wyle et al. (2000); very similar in ash and lipid percentages and slightly higher in moisture and protein percentages.

A raw beef bottom round roast trimmed to $1 / 8$ ” of fat was reported to have 61 $\mathrm{mg} / 100 \mathrm{~g}$ of cholesterol and a raw beef eye of round roast trimmed to $1 / 8$ " of fat was reported to possess $59 \mathrm{mg} / 100 \mathrm{~g}$ of cholesterol (USDA, 2004). These data are in agreement with the cholesterol values in the present study that ranged from 62 to 68 $\mathrm{mg} / 100 \mathrm{~g}$ for pooled Select and premium Choice muscles.

Fatty acid data reported as the weight percentage of fatty acid (g/100g) of total fat extracted used to compare to the beef cuts listed in the USDA SR are listed in Table 4.6. Beef top round steaks trimmed to $1 / 8$ ” fat were reported to have a saturated (SFA), monounsaturated (MUFA), and polyunsaturated (PUFA) content of 1.4, 1.7, and $0.2 \mathrm{~g} / 100 \mathrm{~g}$, respectively (USDA, 2004). Beef bottom round roasts trimmed to 1/8” of fat were reported to possess a SFA, MUFA, and PUFA content of 1.5, 1.8, and $0.2 \mathrm{~g} / 100 \mathrm{~g}$, respectively. In agreement with the data found in the SR, the muscles in the present study had a SFA, MUFA, and PUFA average of 1.5, 1.6, and 0.2 $\mathrm{g} / 100 \mathrm{~g}$, respectively. Stearic acid has been shown to have no effect on blood cholesterol, unlike other SFA that increase serum cholesterol, such as myristic and and palmitic acids (Hegsted et al., 1965; Keys et al., 1965). Monounsaturated fatty acids, such as oleic acid, typically make up half of beef fat (Leheska et al., 2008) and have been shown to exude beneficial health effects on LDL cholesterol levels and 
other cardiovascular disease (CVD) risk factors (Kris-Etherton et al., 1999). Using data from the SR, the beef eye of round roast trimmed to $1 / 8$ ” of fat shows a stearic (C18:0) acid content of $0.3 \mathrm{~g} / 100 \mathrm{~g}$ and an oleic (C18:1) acid content of $1.1 \mathrm{~g} / 100 \mathrm{~g}$ (USDA, 2004). In the present study, the Superficial digital flexor contained the highest proportion of stearic acid, $1 \mathrm{~g} / 100 \mathrm{~g}$, and the remaining muscles possessed an average stearic acid content of $0.5 \mathrm{~g} / 100 \mathrm{~g}$. All muscles in the present study possessed a higher oleic acid content than the eye of round roast, averaging $1.5 \mathrm{~g} / 100 \mathrm{~g}$ across the six muscles. The Adductor muscle contained the highest oleic acid content, and thus highest MUFA and lowest SFA proportion of all muscles evaluated.

French et al. (2000) analyzed the fatty acid composition of 50 steers offered grass, grass silage, or concentrate diets and reported that the stearic acid, oleic acid, and total MUFA content for the raw Longissimus muscle from the concentrate-fed group was 15.95, 38.64, and $41.48 \mathrm{~g} / 100 \mathrm{~g}$, respectively. Leheska et al. (2008) compared the effects of conventional and grass-feeding systems on the nutrient composition of beef and reported a stearic acid and oleic acid content of raw conventionally fed strip steaks of 13.2 and 38.6, respectively. When comparing the muscles in the present study to the strip steaks analyzed by French et al. (2000) and Leheska et al. (2008), the round muscles had a higher stearic and oleic acid content, and a higher total proportion of MUFA. However, the differences in levels of these fatty acids may not be significant in regards to human health.

According to USDA guidelines (2008), a $100 \mathrm{~g}$ serving of beef qualifies as "extra lean" if it has less than $5 \mathrm{~g}$ of total fat, $2 \mathrm{~g}$ or less of saturated fat, and less than $95 \mathrm{mg}$ of cholesterol. It qualifies as "lean" if it has less than $10 \mathrm{~g}$ of total fat, $4.5 \mathrm{~g}$ or 
less of saturated fat, and less than $95 \mathrm{mg}$ of cholesterol. Following these guidelines, the Adductor, Gastrocnemius, Gracilis, Pectineus, and Semimembranosus muscles qualify for the "extra lean" classification, and the Superficial digital flexor qualifies for the "lean” ranking.

\section{Implications}

All of the round muscles evaluated in this study qualified for "extra lean” or "lean" classification according to USDA guidelines that stipulate maximum allowable saturated fat, total fat, and cholesterol contents for a serving of beef (100g). This illustrates the potential for these round muscles to be sold in foodservice operations and retail stores with marketing emphasis being placed on the exceptional leanness of these cuts. 
Table 4.1. Simple means and standard deviations for carcass traits of the experimental sample stratified by quality grade

\begin{tabular}{|c|c|c|c|c|c|c|}
\hline \multirow[b]{2}{*}{ Trait } & \multicolumn{3}{|c|}{ USDA Select } & \multicolumn{3}{|c|}{ Premium USDA Choice } \\
\hline & $\mathrm{n}$ & Mean & SD & $n^{a}$ & Mean & SD \\
\hline Carcass weight, kg & 10 & 311.5 & 28.37 & 9 & 308.4 & 16.76 \\
\hline Adjusted fat thickness, cm & 10 & 1.3 & 0.20 & 9 & 1.7 & 0.10 \\
\hline Ribeye area, $\mathrm{cm}^{2}$ & 10 & 88.4 & 7.81 & 9 & 82.0 & 6.71 \\
\hline Kidney, pelvic, and heart fat, \% & 10 & 2.2 & 0.26 & 9 & 2.0 & 0.00 \\
\hline Calculated USDA yield grade & 10 & 2.5 & 0.50 & 9 & 3.1 & 0.33 \\
\hline Marbling score $^{\mathrm{b}}$ & 10 & 336 & 12.65 & 10 & 517 & 29.08 \\
\hline
\end{tabular}

${ }^{a}$ Values for carcass weight, adjusted fat thickness, ribeye area, and kidney, pelvic, and heart fat were not recorded for one premium Choice carcass.

b 300 to 399 = Slight, 400 to $499=$ Small, 500 to $599=$ Modest, 600 to $699=$ Moderate. 
Table 4.2. Individual beef muscles removed from a carcass, the number of each muscle evaluated, and the subprimal from which each muscle was removed

\begin{tabular}{lccc}
\hline \hline Muscle & $\mathrm{n}$ & Subprimal & $\mathrm{IMPS}^{\mathrm{a}}$ \\
\hline Adductor & 20 & Inside round & 168 \\
Gastrocnemius - medial portion & 20 & Bottom round & $171 \mathrm{~F}$ \\
Gracilis & 20 & Inside round & 168 \\
Pectineus & 20 & Inside round & 168 \\
Semimembranosus & 20 & Inside round & 168 \\
Superficial digital flexor & 20 & Bottom round & $171 \mathrm{~F}$ \\
\hline
\end{tabular}

${ }^{\mathrm{a}}$ IMPS = Institutional Meat Purchase Specifications (USDA, 1996). 
Table 4.3. Means \pm SEM and p-values of raw proximate, cholesterol, and fatty acid ${ }^{\mathrm{a}}$ analyses for five USDA Select and premium USDA Choice beef muscles

\begin{tabular}{|c|c|c|c|c|c|c|c|c|c|c|c|c|c|c|c|}
\hline \multirow[b]{2}{*}{ Fatty acid, \% } & \multicolumn{3}{|c|}{ Adductor } & \multicolumn{3}{|c|}{ Gastrocnemius } & \multicolumn{3}{|c|}{ Gracilis } & \multicolumn{3}{|c|}{ Pectineus } & \multicolumn{3}{|c|}{ Superficial digital flexor } \\
\hline & $\begin{array}{c}\text { Se } \\
\text { Mean } \pm \text { SEM } \\
\end{array}$ & $\begin{array}{c}\text { Ch } \\
\text { Mean } \pm \text { SEM }\end{array}$ & $P$ & $\begin{array}{c}\text { Se } \\
\text { Mean } \pm \text { SEM }\end{array}$ & $\begin{array}{c}\text { Ch } \\
\text { Mean } \pm \text { SEM } \\
\end{array}$ & $P$ & $\begin{array}{c}\text { Se } \\
\text { Mean } \pm \text { SEM } \\
\end{array}$ & $\begin{array}{c}\text { Ch } \\
\text { Mean } \pm \text { SEM } \\
\end{array}$ & $P$ & $\begin{array}{c}\text { Se } \\
\text { Mean } \pm \text { SEM } \\
\end{array}$ & $\begin{array}{c}\text { Ch } \\
\text { Mean } \pm \text { SEM } \\
\end{array}$ & $P$ & $\begin{array}{c}\text { Se } \\
\text { Mean } \pm \text { SEM }\end{array}$ & $\begin{array}{c}\text { Ch } \\
\text { Mean } \pm \text { SEM }\end{array}$ & $P$ \\
\hline C14:0 & $2.44 \pm 0.06$ & $2.44 \pm 0.06$ & 1.00 & $2.49 \pm 0.06$ & $2.48 \pm 0.06$ & 0.92 & $2.52 \pm 0.06$ & $2.56 \pm 0.06$ & 0.62 & $2.53 \pm 0.06$ & $2.62 \pm 0.06$ & 0.35 & $2.59 \pm 0.06$ & $2.53 \pm 0.06$ & 0.46 \\
\hline C14:1 & $0.77 \pm 0.06$ & $0.77 \pm 0.06$ & 0.97 & $0.61 \pm 0.06$ & $0.58 \pm 0.06$ & 0.74 & $0.53 \pm 0.06$ & $0.70 \pm 0.06$ & 0.05 & $0.81 \pm 0.06$ & $0.69 \pm 0.06$ & 0.16 & $0.56 \pm 0.06$ & $0.60 \pm 0.06$ & 0.63 \\
\hline C16:0 & $22.51 \pm 0.48$ & $22.55 \pm 0.48$ & 0.95 & $24.38 \pm 0.48$ & $24.48 \pm 0.48$ & 0.89 & $24.65 \pm 0.48$ & $24.75 \pm 0.48$ & 0.89 & $23.41 \pm 0.48$ & $24.33 \pm 0.48$ & 0.18 & $24.97 \pm 0.48$ & $24.47 \pm 0.48$ & 0.46 \\
\hline C16:1 & $3.90 \pm 0.23$ & $3.89 \pm 0.23$ & 0.97 & $3.29 \pm 0.23$ & $3.18 \pm 0.23$ & 0.74 & $2.90 \pm 0.23$ & $3.51 \pm 0.23$ & 0.07 & $3.99 \pm 0.23$ & $3.41 \pm 0.23$ & 0.08 & $2.95 \pm 0.23$ & $3.27 \pm 0.23$ & 0.34 \\
\hline C17:0 & $1.16 \pm 0.06$ & $1.17 \pm 0.06$ & 0.95 & $1.28 \pm 0.06$ & $1.31 \pm 0.06$ & 0.78 & $1.34 \pm 0.06$ & $1.39 \pm 0.06$ & 0.62 & $1.26 \pm 0.06$ & $1.42 \pm 0.06$ & 0.07 & $1.37 \pm 0.06$ & $1.33 \pm 0.06$ & 0.64 \\
\hline C17:1 & $1.02 \pm 0.03$ & $1.02 \pm 0.03$ & 0.99 & $0.90 \pm 0.03$ & $0.89 \pm 0.03$ & 0.74 & $0.83 \pm 0.03$ & $1.00 \pm 0.03$ & 0.00 & $1.07 \pm 0.03$ & $1.00 \pm 0.03$ & 0.11 & $0.84 \pm 0.03$ & $0.91 \pm 0.03$ & 0.12 \\
\hline C18:0 & $13.99 \pm 0.63$ & $14.05 \pm 0.63$ & 0.95 & $16.13 \pm 0.63$ & $16.76 \pm 0.63$ & 0.48 & $17.89 \pm 0.63$ & $15.87 \pm 0.63$ & 0.03 & $14.32 \pm 0.63$ & $16.47 \pm 0.63$ & 0.02 & $17.90 \pm 0.63$ & $16.41 \pm 0.63$ & 0.10 \\
\hline $\mathrm{t}$-vaccenic & $3.00 \pm 0.34$ & $3.02 \pm 0.34$ & 0.97 & $3.39 \pm 0.34$ & $3.32 \pm 0.34$ & 0.87 & $3.60 \pm 0.34$ & $3.78 \pm 0.34$ & 0.70 & $3.55 \pm 0.34$ & $4.05 \pm 0.34$ & 0.29 & $3.70 \pm 0.34$ & $3.78 \pm 0.34$ & 0.87 \\
\hline C18:1c9 & $42.12 \pm 1.13$ & $42.16 \pm 1.13$ & 0.98 & $40.08 \pm 1.13$ & $39.60 \pm 1.13$ & 0.76 & $38.46 \pm 1.13$ & $38.54 \pm 1.13$ & 0.96 & $41.35 \pm 1.13$ & $38.71 \pm 1.13$ & 0.10 & $37.87 \pm 1.13$ & $39.15 \pm 1.13$ & 0.43 \\
\hline C18:1c11 & $2.13 \pm 0.07$ & $2.12 \pm 0.07$ & 0.94 & $1.91 \pm 0.07$ & $1.88 \pm 0.07$ & 0.80 & $1.79 \pm 0.07$ & $1.95 \pm 0.07$ & 0.11 & $2.09 \pm 0.07$ & $1.94 \pm 0.07$ & 0.13 & $1.77 \pm 0.07$ & $1.90 \pm 0.07$ & 0.20 \\
\hline C18:2 & $5.02 \pm 0.31$ & $5.02 \pm 0.31$ & 0.99 & $4.32 \pm 0.31$ & $4.24 \pm 0.31$ & 0.85 & $4.25 \pm 0.31$ & $4.56 \pm 0.31$ & 0.47 & $4.19 \pm 0.31$ & $4.14 \pm 0.31$ & 0.91 & $4.18 \pm 0.31$ & $4.44 \pm 0.31$ & 0.54 \\
\hline C18:3 & $0.38 \pm 0.05$ & $0.24 \pm 0.05$ & 0.06 & $0.24 \pm 0.05$ & $0.26 \pm 0.05$ & 0.81 & $0.17 \pm 0.05$ & $0.22 \pm 0.05$ & 0.47 & $0.23 \pm 0.05$ & $0.16 \pm 0.05$ & 0.32 & $0.19 \pm 0.05$ & $0.24 \pm 0.05$ & 0.53 \\
\hline C18:2c9t11 & $0.32 \pm 0.02$ & $0.33 \pm 0.02$ & 0.77 & $0.35 \pm 0.02$ & $0.36 \pm 0.02$ & 0.82 & $0.35 \pm 0.02$ & $0.33 \pm 0.02$ & 0.65 & $0.32 \pm 0.02$ & $0.31 \pm 0.02$ & 0.71 & $0.36 \pm 0.02$ & $0.36 \pm 0.02$ & 0.85 \\
\hline C18:2t10c12 & $0.04 \pm 0.01$ & $0.04 \pm 0.01$ & 0.55 & $0.05 \pm 0.01$ & $0.05 \pm 0.01$ & 0.94 & $0.04 \pm 0.01$ & $0.02 \pm 0.01$ & 0.25 & $0.03 \pm 0.01$ & $0.04 \pm 0.01$ & 0.46 & $0.03 \pm 0.01$ & $0.05 \pm 0.01$ & 0.12 \\
\hline C20:4 & $1.06 \pm 0.09$ & $1.05 \pm 0.09$ & 0.97 & $0.46 \pm 0.09$ & $0.50 \pm 0.09$ & 0.78 & $0.59 \pm 0.09$ & $0.71 \pm 0.09$ & 0.32 & $0.76 \pm 0.09$ & $0.63 \pm 0.09$ & 0.32 & $0.59 \pm 0.09$ & $0.47 \pm 0.09$ & 0.31 \\
\hline C24:0 & $0.13 \pm 0.01$ & $0.13 \pm 0.01$ & 0.91 & $0.10 \pm 0.01$ & $0.11 \pm 0.01$ & 0.40 & $0.10 \pm 0.01$ & $0.10 \pm 0.01$ & 0.93 & $0.09 \pm 0.01$ & $0.09 \pm 0.01$ & 0.96 & $0.10 \pm 0.01$ & $0.10 \pm 0.01$ & 0.83 \\
\hline \multicolumn{16}{|c|}{ Proximate analysis, \% } \\
\hline Moisture & $73.79 \pm 0.30$ & $73.20 \pm 0.30$ & 0.17 & $\mathrm{NA}^{\mathrm{b}}$ & $\mathrm{NA}^{\mathrm{b}}$ & $\mathrm{NA}^{\mathrm{b}}$ & $76.28 \pm 0.30$ & $75.27 \pm 0.30$ & 0.02 & $74.47 \pm 0.30$ & $73.78 \pm 0.30$ & 0.10 & $73.19 \pm 0.30$ & $70.95 \pm 0.30$ & $<0.00$ \\
\hline Ash & $1.21 \pm 0.05$ & $1.16 \pm 0.05$ & 0.50 & $\mathrm{NA}^{\mathrm{b}}$ & $\mathrm{NA}^{\mathrm{b}}$ & $\mathrm{NA}^{\mathrm{b}}$ & $1.05 \pm 0.05$ & $1.10 \pm 0.05$ & 0.42 & $1.02 \pm 0.05$ & $1.06 \pm 0.05$ & 0.61 & $0.99 \pm 0.05$ & $0.93 \pm 0.05$ & 0.31 \\
\hline Protein & $24.05 \pm 0.21$ & $23.69 \pm 0.21$ & 0.23 & $\mathrm{NA}^{\mathrm{b}}$ & $\mathrm{NA}^{\mathrm{b}}$ & $\mathrm{NA}^{\mathrm{b}}$ & $21.83 \pm 0.21$ & $21.76 \pm 0.21$ & 0.81 & $23.80 \pm 0.21$ & $23.61 \pm 0.21$ & 0.53 & $22.06 \pm 0.21$ & $22.24 \pm 0.21$ & 0.55 \\
\hline Lipid & $2.52 \pm 0.26$ & $3.07 \pm 0.26$ & 0.13 & $2.13 \pm 0.26$ & $2.55 \pm 0.26$ & 0.25 & $2.57 \pm 0.26$ & $3.27 \pm 0.26$ & 0.06 & $2.08 \pm 0.26$ & $2.69 \pm 0.26$ & 0.09 & $4.95 \pm 0.26$ & $7.40 \pm 0.26$ & $<0.00$ \\
\hline $\begin{array}{l}\text { Cholesterol, } \\
\mathrm{mg} / 100 \mathrm{~g}\end{array}$ & $67.44 \pm 2.01$ & $65.42 \pm 2.01$ & 0.48 & $62.52 \pm 2.01$ & $65.81 \pm 2.01$ & 0.25 & $61.01 \pm 2.01$ & $62.99 \pm 2.01$ & 0.49 & $67.48 \pm 2.01$ & $69.22 \pm 2.01$ & 0.54 & $64.53 \pm 2.01$ & $63.47 \pm 2.01$ & 0.71 \\
\hline
\end{tabular}

${ }^{a}$ Data are reported as the normalized weight percentage of fatty acid.

${ }^{\mathrm{b}}$ The Gastrocnemius muscle was not analyzed for moisture, ash, or protein percentage. 
Table 4.4. Means \pm SEM of raw proximate, cholesterol, and fatty acid ${ }^{1}$ analyses for six combined USDA Select and premium USDA Choice beef muscles

\begin{tabular}{|c|c|c|c|c|c|c|}
\hline \multirow[b]{3}{*}{ Fatty acid, \% } & \multicolumn{6}{|c|}{ Muscles } \\
\hline & Adductor & Gastrocnemius & Gracilis & Pectineus & Semimembranosus & Superficial digital flexor \\
\hline & Mean \pm SEM & Mean \pm SEM & Mean \pm SEM & Mean \pm SEM & Mean \pm SEM & Mean \pm SEM \\
\hline C14:0 & $2.44 \pm 0.05^{\mathrm{a}}$ & $2.49 \pm 0.05^{\mathrm{a}}$ & $2.54 \pm 0.05^{\mathrm{a}}$ & $2.58 \pm 0.05^{\mathrm{a}}$ & $2.57 \pm 0.05^{\mathrm{a}}$ & $2.56 \pm 0.05^{\mathrm{a}}$ \\
\hline C14:1 & $0.77 \pm 0.04^{\mathrm{a}}$ & $0.59 \pm 0.04^{\mathrm{c}}$ & $0.61 \pm 0.04^{\mathrm{c}}$ & $0.75 \pm 0.04^{\mathrm{ab}}$ & $0.65 \pm 0.04^{\mathrm{bc}}$ & $0.58 \pm 0.04^{\mathrm{c}}$ \\
\hline C16:0 & $22.53 \pm 0.31^{\mathrm{c}}$ & $24.43 \pm 0.31^{\mathrm{ab}}$ & $24.70 \pm 0.31^{\mathrm{ab}}$ & $23.87 \pm 0.31^{\mathrm{b}}$ & $24.91 \pm 0.31^{\mathrm{a}}$ & $24.72 \pm 0.31^{\mathrm{ab}}$ \\
\hline C16:1 & $3.90 \pm 0.16^{\mathrm{a}}$ & $3.24 \pm 0.16^{\mathrm{C}}$ & $3.20 \pm 0.16^{\mathrm{c}}$ & $3.70 \pm 0.16^{\mathrm{ab}}$ & $3.53 \pm 0.16^{\mathrm{bc}}$ & $3.11 \pm 0.16^{\mathrm{C}}$ \\
\hline $\mathrm{C} 17: 0$ & $1.16 \pm 0.04^{\mathrm{b}}$ & $1.30 \pm 0.04^{\mathrm{a}}$ & $1.36 \pm 0.04^{\mathrm{a}}$ & $1.34 \pm 0.04^{\mathrm{a}}$ & $1.37 \pm 0.04^{\mathrm{a}}$ & $1.35 \pm 0.04^{\mathrm{a}}$ \\
\hline $\mathrm{C} 17: 1$ & $1.02 \pm 0.02^{\mathrm{ab}}$ & $0.89 \pm 0.02^{\mathrm{d}}$ & $0.92 \pm 0.02^{\mathrm{cd}}$ & $1.03 \pm 0.02^{\mathrm{a}}$ & $0.97 \pm 0.02^{\mathrm{bc}}$ & $0.88 \pm 0.02^{d}$ \\
\hline C18:0 & $14.02 \pm 0.45^{\mathrm{c}}$ & $16.45 \pm 0.45^{\mathrm{ab}}$ & $16.88 \pm 0.45^{\mathrm{a}}$ & $15.40 \pm 0.45^{b}$ & $16.20 \pm 0.45^{\mathrm{ab}}$ & $17.15 \pm 0.45^{\mathrm{a}}$ \\
\hline t-vaccenic & $3.01 \pm 0.23^{\mathrm{a}}$ & $3.36 \pm 0.23^{\mathrm{a}}$ & $3.69 \pm 0.23^{\mathrm{a}}$ & $3.80 \pm 0.23^{\mathrm{a}}$ & $3.57 \pm 0.23^{\mathrm{a}}$ & $3.74 \pm 0.23^{\mathrm{a}}$ \\
\hline C18:1c9 & $42.14 \pm 0.75^{\mathrm{a}}$ & $39.84 \pm 0.75^{b}$ & $38.50 \pm 0.75^{b}$ & $40.03 \pm 0.75^{b}$ & $38.51 \pm 0.75^{\mathrm{b}}$ & $38.51 \pm 0.75^{b}$ \\
\hline C18:1c11 & $2.13 \pm 0.05^{\mathrm{a}}$ & $1.89 \pm 0.05^{\mathrm{bc}}$ & $1.87 \pm 0.05^{\mathrm{c}}$ & $2.01 \pm 0.05^{\mathrm{ab}}$ & $1.90 \pm 0.05^{\mathrm{bc}}$ & $1.84 \pm 0.05^{\mathrm{c}}$ \\
\hline C18:2 & $5.02 \pm 0.23^{\mathrm{a}}$ & $4.28 \pm 0.23^{\mathrm{a}}$ & $4.40 \pm 0.23^{\mathrm{a}}$ & $4.17 \pm 0.23^{\mathrm{a}}$ & $4.60 \pm 0.23^{\mathrm{a}}$ & $4.31 \pm 0.23^{\mathrm{a}}$ \\
\hline C18:3 & $0.31 \pm 0.04^{\mathrm{a}}$ & $0.25 \pm 0.04^{\mathrm{a}}$ & $0.20 \pm 0.04^{\mathrm{a}}$ & $0.19 \pm 0.04^{\mathrm{a}}$ & $0.22 \pm 0.04^{\mathrm{a}}$ & $0.22 \pm 0.04^{\mathrm{a}}$ \\
\hline C18:2c9t11 & $0.32 \pm 0.01^{\mathrm{a}}$ & $0.36 \pm 0.01^{\mathrm{a}}$ & $0.34 \pm 0.01^{\mathrm{a}}$ & $0.32 \pm 0.01^{\mathrm{a}}$ & $0.33 \pm 0.01^{\mathrm{a}}$ & $0.36 \pm 0.01^{\mathrm{a}}$ \\
\hline C18:2t10c12 & $0.04 \pm 0.01^{\mathrm{a}}$ & $0.05 \pm 0.01^{\mathrm{a}}$ & $0.03 \pm 0.01^{\mathrm{a}}$ & $0.04 \pm 0.01^{\mathrm{a}}$ & $0.03 \pm 0.01^{\mathrm{a}}$ & $0.04 \pm 0.01^{\mathrm{a}}$ \\
\hline C20:4 & $1.05 \pm 0.07^{\mathrm{a}}$ & $0.48 \pm 0.07^{\mathrm{c}}$ & $0.65 \pm 0.07^{\mathrm{bc}}$ & $0.69 \pm 0.07^{\mathrm{b}}$ & $0.69 \pm 0.07^{b}$ & $0.53 \pm 0.07^{\mathrm{bc}}$ \\
\hline $\mathrm{C} 24: 0$ & $0.13 \pm 0.01^{\mathrm{a}}$ & $0.10 \pm 0.01^{\mathrm{a}}$ & $0.10 \pm 0.01^{\mathrm{a}}$ & $0.09 \pm 0.01^{\mathrm{a}}$ & $0.12 \pm 0.01^{\mathrm{a}}$ & $0.10 \pm 0.01^{\mathrm{a}}$ \\
\hline SFA Total & 40.29 & 44.77 & 45.59 & 43.27 & 45.17 & 45.89 \\
\hline MUFA Total & 52.96 & 49.81 & 48.79 & 51.32 & 48.95 & 48.66 \\
\hline PUFA Total & 6.75 & 5.42 & 5.62 & 5.41 & 5.88 & 5.46 \\
\hline Proximate analysis, \% & & & & & & \\
\hline Moisture & $73.49 \pm 0.25^{\mathrm{a}}$ & $\mathrm{NA}^{2}$ & $75.77 \pm 0.25^{b}$ & $74.13 \pm 0.25^{\mathrm{c}}$ & $72.72 \pm 0.25^{\mathrm{d}}$ & $72.07 \pm 0.25^{\mathrm{e}}$ \\
\hline Ash & $1.19 \pm 0.03^{\mathrm{a}}$ & $\mathrm{NA}^{2}$ & $1.07 \pm 0.03^{\mathrm{b}}$ & $1.04 \pm 0.03^{\mathrm{bc}}$ & $1.05 \pm 0.03^{\mathrm{C}}$ & $0.96 \pm 0.03^{\mathrm{b}}$ \\
\hline Protein & $23.87 \pm 0.14^{\mathrm{a}}$ & $\mathrm{NA}^{2}$ & $21.79 \pm 0.14^{\mathrm{d}}$ & $23.71 \pm 0.14^{\mathrm{a}}$ & $23.21 \pm 0.14^{b}$ & $22.15 \pm 0.14^{\mathrm{C}}$ \\
\hline Lipid & $2.80 \pm 0.22^{\mathrm{cd}}$ & $2.34 \pm 0.22^{\mathrm{d}}$ & $2.92 \pm 0.22^{\mathrm{C}}$ & $2.38 \pm 0.22^{\mathrm{cd}}$ & $3.51 \pm 0.22^{\mathrm{b}}$ & $6.18 \pm 0.22^{\mathrm{a}}$ \\
\hline Cholesterol, mg/100g & $66.43 \pm 1.37^{\mathrm{ab}}$ & $64.17 \pm 1.37^{\mathrm{bc}}$ & $62.00 \pm 1.37^{\mathrm{c}}$ & $68.35 \pm 1.37^{\mathrm{a}}$ & $62.67 \pm 1.37^{\mathrm{bc}}$ & $64.00 \pm 1.37^{\mathrm{bc}}$ \\
\hline
\end{tabular}

${ }^{1}$ Data are reported as the normalized weight percentage of fatty acid.

2 The Gastrocnemius muscle was not analyzed for moisture, ash, or protein percentage.

${ }^{\text {abcd }}$ Within a row, means without a common superscript letter differ $(\mathrm{P}<0.05)$. 
Table 4.5. Means \pm SEM of raw proximate and fatty acid ${ }^{1}$ analyses ${ }^{2}$ with significant quality grade effects between USDA Select and premium USDA Choice beef muscles

\begin{tabular}{|c|c|c|c|c|c|c|c|c|c|c|}
\hline \multirow[b]{2}{*}{ Fatty acid, \% } & \multicolumn{2}{|c|}{ Adductor } & \multicolumn{2}{|c|}{ Gastrocnemius } & \multicolumn{2}{|c|}{ Gracilis } & \multicolumn{2}{|c|}{ Pectineus } & \multicolumn{2}{|c|}{ Superficial digital flexor } \\
\hline & $\begin{array}{c}\text { Se } \\
\text { Mean } \pm \text { SEM }\end{array}$ & Ch Mean \pm SEM & $\begin{array}{c}\text { Se } \\
\text { Mean } \pm \text { SEM }\end{array}$ & $\begin{array}{c}\text { Ch } \\
\text { Mean } \pm \text { SEM }\end{array}$ & $\begin{array}{c}\text { Se } \\
\text { Mean } \pm \text { SEM }\end{array}$ & Ch Mean \pm SEM & $\begin{array}{c}\text { Se } \\
\text { Mean } \pm \text { SEM }\end{array}$ & $\begin{array}{c}\text { Ch } \\
\text { Mean } \pm \text { SEM }\end{array}$ & $\begin{array}{c}\text { Se } \\
\text { Mean } \pm \text { SEM }\end{array}$ & $\begin{array}{c}\text { Ch } \\
\text { Mean } \pm \text { SEM }\end{array}$ \\
\hline C17:1 & $1.02 \pm 0.03^{\mathrm{a}}$ & $1.02 \pm 0.03^{\mathrm{a}}$ & $0.90 \pm 0.03^{\mathrm{b}}$ & $0.89 \pm 0.03^{\mathrm{b}}$ & $0.83 \pm 0.03^{\mathrm{b}}$ & $1.00 \pm 0.03^{\mathrm{a}}$ & $1.07 \pm 0.03^{\mathrm{a}}$ & $1.00 \pm 0.03^{\mathrm{a}}$ & $0.84 \pm 0.03^{\mathrm{b}}$ & $0.91 \pm 0.03^{\mathrm{b}}$ \\
\hline C18:0 & $13.99 \pm 0.63^{\mathrm{d}}$ & $14.05 \pm 0.63^{\mathrm{d}}$ & $16.13 \pm 0.63^{\mathrm{ab}}$ & $16.76 \pm 0.63^{\mathrm{ab}}$ & $17.89 \pm 0.63^{\mathrm{a}}$ & $15.87 \pm 0.63^{\mathrm{bc}}$ & $14.32 \pm 0.63^{\text {cd }}$ & $16.47 \pm 0.63^{\mathrm{ab}}$ & $17.90 \pm 0.63^{\mathrm{a}}$ & $16.41 \pm 0.63^{\mathrm{ab}}$ \\
\hline \multicolumn{11}{|c|}{ Proximate analysis, \% } \\
\hline Moisture & $73.79 \pm 0.30^{\text {cd }}$ & $73.20 \pm 0.30^{\mathrm{d}}$ & NA & NA & $76.28 \pm 0.30^{\mathrm{a}}$ & $75.27 \pm 0.30^{\mathrm{b}}$ & $74.47 \pm 0.30^{\mathrm{bc}}$ & $73.78 \pm 0.30^{\text {cd }}$ & $73.19 \pm 0.30^{\mathrm{d}}$ & $70.95 \pm 0.30^{\mathrm{e}}$ \\
\hline Lipid & $2.52 \pm 0.26^{\mathrm{de}}$ & $3.07 \pm 0.26^{\mathrm{cd}}$ & $2.13 \pm 0.26^{\mathrm{e}}$ & $2.55 \pm 0.26^{\mathrm{de}}$ & $2.57 \pm 0.26^{\text {cde }}$ & $3.27 \pm 0.26^{\mathrm{c}}$ & $2.08 \pm 0.26^{\mathrm{e}}$ & $2.69 \pm 0.26^{\text {cde }}$ & $4.95 \pm 0.26^{\mathrm{b}}$ & $7.40 \pm 0.26^{\mathrm{a}}$ \\
\hline
\end{tabular}

${ }^{1}$ Data are reported as the normalized weight percentage of the fatty acid.

${ }^{2}$ Analyses suggested a significant $(P<0.05)$ interaction for effects of quality grade and muscle.

${ }^{\text {abcd }}$ Within a row, means without a common superscript letter differ $(P<0.05)$. 
Table 4.6. Means \pm SEM of raw fatty acid $^{1}$ (g/100g) analysis for six combined USDA Select and premium USDA Choice beef muscles

\begin{tabular}{|c|c|c|c|c|c|c|}
\hline \multirow[b]{2}{*}{$\begin{array}{l}\text { Fatty acid, } \\
\text { g/100g }\end{array}$} & \multicolumn{6}{|c|}{ Muscles } \\
\hline & $\begin{array}{c}\text { Adductor } \\
\text { Mean } \pm \text { SEM }\end{array}$ & $\begin{array}{l}\text { Gastrocnemius } \\
\text { Mean } \pm \text { SEM }\end{array}$ & $\begin{array}{c}\text { Gracilis } \\
\text { Mean } \pm \text { SEM }\end{array}$ & $\begin{array}{c}\text { Pectineus } \\
\text { Mean } \pm \text { SEM }\end{array}$ & $\begin{array}{l}\text { Semimembranosus } \\
\text { Mean } \pm \text { SEM }\end{array}$ & $\begin{array}{c}\text { Superficial digital flexor } \\
\text { Mean } \pm \text { SEM }\end{array}$ \\
\hline C14:0 & $0.069 \pm 0.005^{\mathrm{cd}}$ & $0.058 \pm 0.005^{\mathrm{d}}$ & $0.074 \pm 0.005^{\mathrm{c}}$ & $0.062 \pm 0.005^{\mathrm{cd}}$ & $0.090 \pm 0.005^{\mathrm{b}}$ & $0.157 \pm 0.005^{\mathrm{a}}$ \\
\hline $\mathrm{C} 14: 1$ & $0.022 \pm 0.002^{\mathrm{b}}$ & $0.014 \pm 0.002^{c}$ & $0.018 \pm 0.002^{\mathrm{bc}}$ & $0.017 \pm 0.002^{\mathrm{bc}}$ & $0.023 \pm 0.002^{\mathrm{b}}$ & $0.037 \pm 0.002^{\mathrm{a}}$ \\
\hline C16:0 & $0.632 \pm 0.054^{\mathrm{cd}}$ & $0.573 \pm 0.054^{\mathrm{d}}$ & $0.722 \pm 0.054^{\mathrm{c}}$ & $0.572 \pm 0.054^{d}$ & $0.873 \pm 0.054^{b}$ & $1.522 \pm 0.054^{\mathrm{a}}$ \\
\hline C16:1 & $0.109 \pm 0.011 b^{c}$ & $0.075 \pm 0.011^{\mathrm{d}}$ & $0.094 \pm 0.011^{\text {bcd }}$ & $0.086 \pm 0.011^{\mathrm{cd}}$ & $0.118 \pm 0.011^{\mathrm{b}}$ & $0.197 \pm 0.011^{\mathrm{a}}$ \\
\hline $\mathrm{C} 17: 0$ & $0.033 \pm 0.003^{\mathrm{cd}}$ & $0.031 \pm 0.003^{\mathrm{d}}$ & $0.040 \pm 0.003^{\mathrm{c}}$ & $0.033 \pm 0.003^{\mathrm{cd}}$ & $0.048 \pm 0.003^{b}$ & $0.082 \pm 0.003^{\mathrm{a}}$ \\
\hline C17:1 & $0.029 \pm 0.002^{\mathrm{bc}}$ & $0.021 \pm 0.002^{\mathrm{d}}$ & $0.027 \pm 0.002^{\mathrm{C}}$ & $0.024 \pm 0.002^{\mathrm{cd}}$ & $0.034 \pm 0.002^{b}$ & $0.055 \pm 0.002^{\mathrm{a}}$ \\
\hline C18:0 & $0.394 \pm 0.035^{c}$ & $0.386 \pm 0.035^{c}$ & $0.490 \pm 0.035^{\mathrm{b}}$ & $0.374 \pm 0.035^{c}$ & $0.564 \pm 0.035^{b}$ & $1.041 \pm 0.035^{\mathrm{a}}$ \\
\hline t-vaccenic & $0.084 \pm 0.010^{\mathrm{cd}}$ & $0.079 \pm 0.010^{\mathrm{d}}$ & $0.108 \pm 0.010^{\mathrm{bc}}$ & $0.094 \pm 0.010^{\mathrm{cd}}$ & $0.123 \pm 0.010^{b}$ & $0.227 \pm 0.010^{\mathrm{a}}$ \\
\hline C18:1c9 & $1.177 \pm 0.092^{\mathrm{bc}}$ & $0.931 \pm 0.092^{\mathrm{d}}$ & $1.125 \pm 0.092^{\text {bcd }}$ & $0.944 \pm 0.092^{\mathrm{cd}}$ & $1.350 \pm 0.092^{\mathrm{a}}$ & $2.395 \pm 0.092^{\mathrm{b}}$ \\
\hline C18:1c11 & $0.060 \pm 0.005^{\mathrm{bc}}$ & $0.044 \pm 0.005^{\mathrm{d}}$ & $0.055 \pm 0.005^{\text {bcd }}$ & $0.047 \pm 0.005^{\mathrm{cd}}$ & $0.067 \pm 0.005^{b}$ & $0.115 \pm 0.005^{\mathrm{a}}$ \\
\hline C18:2 & $0.140 \pm 0.014^{\mathrm{b}}$ & $0.099 \pm 0.014^{c}$ & $0.129 \pm 0.014^{\mathrm{bc}}$ & $0.099 \pm 0.014^{c}$ & $0.166 \pm 0.014^{\mathrm{b}}$ & $0.270 \pm 0.014^{\mathrm{a}}$ \\
\hline C18:3 & $0.008 \pm 0.001^{b}$ & $0.006 \pm 0.001^{\mathrm{bc}}$ & $0.006 \pm 0.001^{\mathrm{bc}}$ & $0.004 \pm 0.001^{c}$ & $0.008 \pm 0.001^{b}$ & $0.013 \pm 0.001^{\mathrm{a}}$ \\
\hline C18:2c9t11 & $0.009 \pm 0.001^{c}$ & $0.008 \pm 0.001^{\mathrm{c}}$ & $0.010 \pm 0.001^{\mathrm{bc}}$ & $0.008 \pm 0.001^{\mathrm{c}}$ & $0.011 \pm 0.001^{b}$ & $0.022 \pm 0.001^{\mathrm{a}}$ \\
\hline C18:2t10c12 & $0.001 \pm 0.000^{\mathrm{a}}$ & $0.001 \pm 0.000^{\mathrm{a}}$ & $0.001 \pm 0.000^{\mathrm{a}}$ & $0.001 \pm 0.000^{\mathrm{a}}$ & $0.001 \pm 0.000^{\mathrm{a}}$ & $0.003 \pm 0.000^{\mathrm{b}}$ \\
\hline C20:4 & $0.029 \pm 0.003^{\mathrm{a}}$ & $0.011 \pm 0.003^{\mathrm{d}}$ & $0.019 \pm 0.003^{\mathrm{bc}}$ & $0.016 \pm 0.003^{\mathrm{cd}}$ & $0.026 \pm 0.003^{\mathrm{ab}}$ & $0.033 \pm 0.003^{\mathrm{a}}$ \\
\hline $\mathrm{C} 24: 0$ & $0.004 \pm 0.000^{\mathrm{bc}}$ & $0.002 \pm 0.000^{\mathrm{cd}}$ & $0.003 \pm 0.000^{\mathrm{cd}}$ & $0.002 \pm 0.000^{\mathrm{d}}$ & $0.004 \pm 0.000^{\mathrm{b}}$ & $0.006 \pm 0.000^{\mathrm{a}}$ \\
\hline SFA Total & 1.130 & 1.050 & 1.329 & 1.043 & 1.578 & 2.808 \\
\hline MUFA Total & 1.480 & 1.108 & 1.359 & 1.156 & 1.715 & 2.882 \\
\hline PUFA Total & 0.179 & 0.120 & 0.157 & 0.122 & 0.213 & 0.325 \\
\hline
\end{tabular}

${ }^{1}$ Data are reported as the weight percentage of fatty acid $(\mathrm{g} / 100 \mathrm{~g})$ of total fat extracted.

${ }^{\text {abcd }}$ Within a row, means without a common superscript letter differ $(P<0.05)$. 


\section{CHAPTER V}

\section{LITERATURE CITED}

Aberle, E.D., E.S. Reeves, M.D. Judge, R.E. Hunsley, and T.W. Perry. 1981. Palatability and muscle characteristics of cattle with controlled weight gain: Time on a high energy diet. J. Anim. Sci. 52:757-763.

Aberle, E.D., J.C. Forrest, D.E. Gerrard, and E.W. Mills. 2001. Principles of Meat Science. $4^{\text {th }}$ ed. Kendall/Hunt, Dubuque, IA.

Alexander, D.D. and C.A. Cushing. 2010. Red meat and colorectal cancer: A critical summary of prospective epidemiologic studies. Obes. Rev. no. doi: 10.1111/j.1467-789X.2010.00785.x:1-22.

AOAC. 1995. Removal of moisture, official method 8.2.1.1. $16^{\text {th }}$ ed. Assoc. Off. Anal. Chem., Arlington, VA.

AOAC. 2000. Official methods of analysis. 17th ed. Assoc. Off. Anal. Chem., Arlington, VA.

Bandman, E. and D. Zdanis. 1988. An immunological method to assess protein degradation in post-mortem muscle. Meat Sci. 22:1-19.

Bhattacharya, A., J. Banu, M. Rahman, J. Causey, and G. Fernandes. 2006. Biological effects of conjugated linoleic acids in health and disease. J. Nutr. Biochem. 17:789-810.

Bligh, E.G. and W.J. Dyer. 1959. A rapid method of total lipid extraction and purification. Can. J. Physiol. Pharmacol. 37:911-917.

Boleman, S.J., S.L. Boleman, R.K. Miller, J.F. Taylor, H.R. Cross, T.L. Wheeler, M. Koohmaraie, S.D. Shackelford, M.F. Miller, R.L. West, D.D. Johnson, and J.W. Savell. 1997. Consumer evaluation of beef of known categories of tenderness. J. Anim. Sci. 75:1521-1524.

Bratcher, C.L., D.D. Johnson, R.C. Littell, and B.L. Gwartney. 2005. The effects of quality grade, aging, and location within muscle on Warner-Bratzler shear force in beef muscles of locomotion. Meat Sci. 70:279-284. 
Bratzler, L.J. and H.D. Smith. 1963. A comparison of the press method with tastepanel shear measurements of tenderness in beef and lamb muscles. J. Food Sci. 28:99-100.

Busch, W.A., F.C. Parrish, Jr., and D.E. Goll. 1967. Molecular properties of postmortem muscle. 4. Effect of temperature on adenosine triphosphate degradation, isometric tension parameters, and shear resistance of bovine muscle. J. Food Sci. 32:390-394.

Busch, W.A., M.H. Stromer, D.E. Goll, and A. Suzuki. 1972. $\mathrm{Ca}^{2+}$-specific removal of z lines from rabbit skeletal muscle. J. Cell Biol. 52:367-381.

Calkins, C.R. and S.C. Seideman. 1988. Relationships among calcium-dependent protease, cathepsins $\mathrm{B}$ and $\mathrm{H}$, meat tenderness and the response of muscle to aging. J. Anim. Sci. 66:1186-1193.

Cattlemen's Beef Board. 2008. Understanding the Different Kinds of Beef in the Marketplace. http://www.beefresearch.org/CMDocs/BeefResearch/ Beef\%20Choices.pdf. Accessed Oct. 13, 2010.

Cattlemen's Beef Board and National Cattlemen's Beef Association. 2009. Beef Checkoff-Funded Nutrient Database Improvement Research Frequently Asked Questions. http://www.beefresearch.org/CMDocs/BeefResearch/ NDI_FAQs\%20final\%20for\%20web.pdf. Accessed Oct. 13, 2010.

Chin, S.F., W. Liu, J.M. Storkson, Y.L. Ha, and M.W. Pariza. 1992. Dietary sources of conjugated dienoic isomers of linoleic acid, a newly recognized class of anticarcinogens. J. Food Comp. Anal. 5:185-197.

Chizzolini, R., D.A. Ledward, and R.A. Lawrie. 1977. Note on the effect of ageing on the netural salt and acid soluble collagen from the intramuscular connective tissue of various species. Meat Sci. 1:111-117.

Cottin, P., S. Poussard, D. Mornet, J.J. Brustis, M. Mohammadpour, J. Leger, and A. Ducastaing. 1992. In vitro digestion of dystrophin by calcium-dependent proteases, calpains I and II. Biochimie. 74:565-570.

Cotton, P.A., A. F. Subar, J.E. Friday, A. Cook. 2004. Dietary sources of nutrients among US adults, 1994 to 1996. J. Am. Diet. Assoc. 104:921-930.

Cover, S., R.L. Hostetler, and S.J. Ritchey. 1962. Tenderness of beef. IV. Relations of shear force and fiber extensibility to juiciness and six components of tenderness. J. Food. Sci. 27:527-536. 
Craig, S.W. and J.V. Pardo. 1983. Gamma actin, spectrin, and intermediate filament proteins colocalize with vinculin at costameres, myofibril-tosarcolemma attachment sites. Cell Mot. 3:449-462.

Cross, A.J., L.M. Ferrucci, A. Risch, B.I. Graubard, M.H. Ward, Y. Park, A.R. Hollenbeck, A. Schatzkin, and R. Sinha. 2010. A large prospective study of meat consumption and colorectal cancer risk: An investigation of potential mechanisms underlying this association. Cancer Res. 70:2406-2414.

Cross, H.R., M.S. Stanfield, and E.J. Koch. 1976. Beef palatability as affected by cooking rate and final internal temperature. J. Anim. Sci. 43:114-121.

Crouse, J.D. and M. Koohmaraie. 1990. Effect of post-cooking storage conditions on shear-force values of beef steaks. J. Food Sci. 55:858,860.

Culler, R.D., F.C. Parrish, Jr., G.C. Smith, and H.R. Cross. 1978. Relationship of myofibril fragmentation index to certain chemical, physical and sensory characteristics of bovine longissimus muscle. J. Food Sci. 43:1177-1180.

Davis, G.W., G.C. Smith, Z.L. Carpenter, T.R. Dutson, and H.R. Cross. 1979. Tenderness variations among beef steaks from carcasses of the same USDA quality grade. J. Anim. Sci. 49:103-114.

Dransfield, E., D.K. Lockyer, and P. Prabhakaran. 1986. Changes in extensibility of raw beef muscle during storage. Meat Sci. 16:127-142.

Duckett, S.K., D.G. Wagner, L.D. Yates, H.G. Dolezal, and S.G. May. 1993. Effects of time on feed on beef nutrient composition. J. Anim. Sci. 71:20792088.

Dutson, T.R. 1983. Relationship of $\mathrm{pH}$ and temperature to disruption of specific muscle proteins and activity of lysosomal proteases. J. Food Biochem. $7: 223-245$.

Etherington, D.J., M. Taylor, and E. Dransfield. 1987. Conditioning of meat from different species. Relationship between tenderizing and the levels of cathepsin B, cathepsin L, calpain I, calpain II and $\beta$-glucuronidase. Meat Sci. 20:1-18.

Feidt, C., A. Petit, F. Bruas-Reignier, and J. Brun-Bellut. 1996. Release of free amino-acids during ageing in bovine meat. Meat Sci. 44:19-25.

Folch, J., M. Lees, and G.H. Sloane Stanley. 1957. A simple method for the isolation and purification of total lipids from animal tissues. J. Biol. Chem. 226:497-509. 
French, P., C. Stanton, F. Lawless, E.G. O’Riordan, F.J. Monahan, P.J. Caffrey, and A.P. Moloney. 2000. Fatty acid composition, including conjugated linoleic acid, of intramuscular fat from steers offered grazed grass, grass silage, or concentrate-based diets. J. Anim. Sci. 78:2849-2855.

George, M.H., J.D. Tatum, K.E. Belk, and G.C. Smith. 1999. An audit of retail beef loin steak tenderness conducted in eight U.S. cities. J. Anim. Sci. 77:1735-1741.

Goll, D.E., D. W. Henderson, and E.A. Kline. 1964. Post-mortem changes in physical and chemical properties of bovine muscle. J. Food Sci. 29:590-596.

Goll, D.E., Y. Otsuka, A. Nagainis, J.D. Shannon, S.K. Sathe, and M. Muguruma. 1983. Role of muscle proteinases in maintenance of muscle integrity and mass. J. Food Biochem. 7:137-141.

Goll, D.E., R.G. Taylor, J.A. Christiansen, and V.F. Thompson. 1991. Role of proteinases and protein turnover in muscle growth and meat quality. Proc. $44^{\text {th }}$ Annu. Recip. Meat Conf. Natl. Livest. and Meat Board, Chicago, IL. 25-36.

Goll, D.E., M.L. Boehm, G.H. Geesink, and V.F. Thompson. 1997. What causes postmortem tenderization? Proc. $50^{\text {th }}$ Annu. Recip. Meat Conf. Natl. Livest. and Meat Board, Chicago, IL. 60-67.

Greaser, M.L. 1997. Postmortem changes in extracellular matrix proteins. Proc. $50^{\text {th }}$ Annu. Recip. Meat Conf. Natl. Livest. and Meat Board, Chicago, IL. 53-59.

Gruber, S.L., J.D. Tatum, J.A. Scanga, P.L. Chapman, G.C. Smith, and K.E. Belk. 2006. Effects of postmortem aging and USDA quality grade on WarnerBratzler shear force values of seventeen individual beef muscles. J. Anim. Sci. 84:3387-3396.

Hegsted, D.M., R.B. McGandy, M.L. Myers, and F.J. Stare. 1965. Quantitative effects of dietary fat on serum cholesterol in man. Am. J. Clin. Nutr. 17:281295.

Hitchcock, S.E., H.E. Huxley, and A.G. Szent-Gyorgyi. 1973. Calcium sensitive binding of troponin to actin-tropomyosin: A two-site model for troponin action. J. Mol. Biol. 80:825-836.

Ho. C.Y., M.H. Stromer, and R.M. Robson. 1994. Identification of the $30 \mathrm{kDa}$ polypeptide in post mortem skeletal muscle as a degradation product of troponin-T. Biochimie. 76:369-375. 
Hostetler, R.L., B.A. Link, W.A. Landmann, and H.A. Fitzhugh, Jr. 1973. Effect of carcass suspension method on sensory panel scores for some major bovine muscles. J. Food Sci. 38:264-267.

Huff-Lonergan, E., F.C. Parrish, Jr., and R.M. Robson. 1995. Effects of postmortem aging time, animal age, and sex on degradation of titin and nebulin in bovine longissimus muscle. J. Anim. Sci. 73:1064-1073.

Huxley, R.R., A. Ansary-Moghaddam, P. Clifton, S. Czernichow, C.L. Parr, and M. Woodward. 2009. The impact of dietary and lifestyle risk factors on risk of colorectal cancer: A quantitative overview of the epidemiological evidence. Int. J. Cancer. 125:171-180.

Ip, C., Y. Dong, M.M. Ip, S. Banni, G. Carta, E. Angioni, E. Murru, S. Spada, M.P. Melis, and A. Saebo. 2002. Conjugated linoleic acid isomers and mammary cancer prevention. Nutr. Cancer. 43:52-58.

Keys, A., J.T. Anderson, and F. Grande. 1965. Serum cholesterol response to changes in the diet. IV. Particular saturated fatty acids in the diet. Metabolism. 14:776-787.

Koohmaraie, M., S.C. Seideman, J.E. Schollmeyer, T.R. Dutson, and J.D. Crouse. 1987. Effect of post-mortem storage on $\mathrm{Ca}++$ - dependent proteases, their inhibitor, and myofibril fragmentation. Meat Sci. 19:187-196.

Koohmaraie, M. 1988. The role of endogenous proteases in meat tenderness. Proc. $41^{\text {st }}$ Annu. Recip. Meat Conf. Natl. Livest. and Meat Board, Chicago, IL. 89-100.

Koohmaraie, M., A.S. Babiker, R.A. Merkel, and T.R. Dutson. 1988a. Role of $\mathrm{Ca}++-$ dependent proteases and lysosomal enzymes in postmortem changes in bovine skeletal muscle. J. Food Sci. 53:1253-1257.

Koohmaraie, M., A.S. Babiker, A.L. Schroeder, R.A. Merkel, and T.R. Dutson. 1988b. Acceleration of postmortem tenderization in ovine carcasses through activation of $\mathrm{Ca}^{2+}$-dependent proteases. J. Food Sci. 53:1638-1641.

Koohmaraie, M. 1994. Muscle Proteinases and Meat Aging. Meat Sci. 36:93-104.

Koohmaraie, M. 1996. Biochemical factors regulating the toughening and tenderization processes of meat. Meat Sci. 43:S193-S201. 
Koohmaraie, M., M.E. Doumit, and T.L. Wheeler. 1996. Meat toughening does not occur when rigor shortening is prevented. J. Anim. Sci. 74:2935-2942.

Koretz, J.F., T.C. Irving, and K. Wang. 1993. Filamentous aggregates of native titin and binding of C-protein and AMP-deaminase. Arch. Biochem. Biophys. 304:305-309.

Kris-Etherton, P.M., T.A. Pearson, Y. Wan, R.L. Hargrove, K. Moriarty, V. Fishell, and T.D. Etherton. 1999. High-monounsaturated fatty acid diets lower both plasma cholesterol and triacylglycerol concentrations. Am. J. Clin. Nutr. 70:1009-1015.

Lee, K.W., H.J. Lee, H.Y. Cho, and Y.J. Kim. 2005. Role of the conjugated linoleic acid in the prevention of cancer. Crit. Rev. Food Sci. Nutr. 45:135144.

Leheska, J.M., L.D. Thompson, J.C. Howe, E. Hentges, J. Boyce, J.C. Brooks, B. Shriver, L. Hoover, and M.F. Miller. 2008. Effects of conventional and grass-feeding systems on the nutrient composition of beef. J. Anim. Sci. 86:3575-3585.

Marsh, B.B. and N.G. Leet. 1966. Studies in meat tenderness. III. The effects of cold shortening on tenderness. J. Food Sci. 31:450-459.

McKeith, F.K., D.L. De Vol, R.S. Miles, P.J. Bechtel, and T.R. Carr. 1985. Chemical and sensory properties of thirteen major beef muscles. J. Food Sci. 50:869-872.

Miller, M.F., M.A. Carr, C.B. Ramsey, K.L. Crockett, and L.C. Hoover. 2001. Consumer thresholds for establishing the value of beef tenderness. J. Anim. Sci. 79:3062-3068.

Møller, A.J., T. Vestergaard, and J. Wismer-Pedersen. 1973. Myofibril fragmentation in bovine Longissiumus dorsi as an index of tenderness. J. Food Sci. 38:824-825.

Neely, T.R., C.L. Lorenzen, R.K. Miller, J.D. Tatum, J.W. Wise, J. F. Taylor, M.J. Buyck, J.O. Reagan, and J.W. Savell. 1998. Beef customer satisfaction: Role of cut, USDA quality grade, and city on in-home consumer ratings. J. Anim. Sci. 76:1027-1033.

Nishimura, T., A. Hattori, and K. Takahashi. 1995. Structural weakening of intramuscular connective tissue during conditioning of beef. Meat Sci. 39:127-133. 
Nishimura, T., A. Liu, A. Hattori, and K. Takahashi. 1998. Changes in mechanical strength of intramuscular connective tissue during postmortem aging of beef. J. Anim. Sci. 76:528-532.

O’Connor, S.F., J.D. Tatum, D.M. Wulf, R.D. Green, and G.C. Smith. 1997. Genetic effects on beef tenderness in Bos indicus composite and Bos taurus cattle. J. Anim. Sci. 75:1822-1830.

Olson, D.G., F.C. Parrish, Jr., and M.H. Stromer. 1976. Myofibril fragmentation and shear resistance of three bovine muscles during postmortem storage. J. Food Sci. 41:1036-1041.

Olson, D.G. and F.C. Parrish, Jr. 1977. Relationship of myofibril fragmentation index to measures of beefsteak tenderness. J. Food Sci. 42:506-509.

O’Shea, J.M., R.M. Robson, M.K. Hartzer, T.W. Huiatt, W.E. Rathbun, and M.H. Stromer. 1981. Purification of desmin from adult mammalian skeletal muscle. Biochem. J. 195:345-356.

Otremba, M.M., M.E. Dikeman, G.A. Milliken, S.L. Stroda, J.A. Unruh, and E. Chambers, IV. 1999. Interrelationships among evaluations of beef longissimus and semitendinosus muscle tenderness by Warner-Bratzler shear force, a descriptive-texture profile sensory panel, and a descriptive attribute sensory panel. J. Anim. Sci. 77:865-873.

Park, P.W. and R.E. Goins. 1994. In situ preparation of fatty acid methyl esters for analysis of fatty acid composition in foods. J. Food Sci. 59: 1262-1266.

Parrish, Jr., F.C., D.G. Olson, B.E. Miner, and R.E. Rust. 1973. Effect of degree of marbling and internal temperature of doneness on beef rib steaks. J. Anim. Sci. 37:430-434.

Parrish, Jr., F.C., C.J. Vandell, and R.D. Culler. 1979. Effect of maturity and marbling on the myofibril fragmentation index of bovine longissimus muscle. J. Food Sci. 44:1668-1671.

Penny, I.F. and E. Dransfield. 1979. Relationship between toughness and troponin $\mathrm{T}$ in conditioned beef. Meat Sci. 3:135-141.

Pierson, C.J. and J.D. Fox. 1976. Effect of postmortem aging time and temperature on $\mathrm{pH}$, tenderness and soluble collagen fractions in bovine longissimus muscle. J. Anim. Sci. 43:1206-1210. 
Platter, W.J., J.D. Tatum, K.E. Belk, P.L. Chapman, J.A. Scanga, and G.C. Smith. 2003. Relationships of consumer sensory ratings, marbling score, and shear force value to consumer acceptance of beef strip loin steaks. J. Anim. Sci. 81:2741-2750.

Platter, W.J., J.D. Tatum, K.E. Belk, S.R. Koontz, P.L. Chapman, and G.C. Smith. 2005. Effects of marbling and shear force on consumers' willingness to pay for beef strip loin steaks. J. Anim. Sci. 83:890-899.

Ramsbottom, J.M. and E.J. Strandine. 1948. Comparative tenderness and identification of muscles in wholesale beef cuts. J. Food Sci. 13:315-330.

Reuter, B.J., D.M. Wulf, and R.J. Maddock. 2002. Mapping intramuscular tenderness variation in four major muscles of the beef round. J. Anim. Sci. 80:2594-2599.

Richardson, F.L., M.H. Stromer, T.W. Huiatt, and R.M. Robson. 1981. Immunoelectron and immunofluorescence localization of desmin in mature avian muscles. Eur. J. Cell. Biol. 26:91-101.

Ritchey, S.J. and R.L. Hostetler. 1965. The effect of small temperature changes on two beef muscles as determined by panel scores and shear-force values. Food Technol. 19:1275-1278.

Robson, R.M, J.M. O’Shea, M.K. Hartzer, W.E. Rathbun, F. Lasalle, P.J. Schreiner, L.E. Kasang, M.H. Stromer, M.L. Lusby, J.F. Ridpath, Y.Y.Pang, R.R. Evans, M.G. Zeece, F.C. Parrish, and T.W. Huiatt. 1984. Role of new cytoskeletal elements in maintenance of muscle integrity. J. Food Biochem. 8:1-24.

Santarelli, R.L., F. Pierre, and D.E. Corpet. 2008. Processed meat and colorectal cancer: A review of epidemiologic and experimental evidence. Nutr. Cancer. 60:131-144.

Senaratne, L.S., C.R. Calkins, A.S. de Mello, Jr., J.H. Hinkle, and S. Pokharel. 2010. Intramuscular tenderness mapping and muscle fiber directions of small muscles in the beef round. Nebraska Beef Report.118-122.

Shackelford, S.D., J.B. Morgan, H.R. Cross, and J.W. Savell. 1991. Identification of threshold levels for Warner-Bratzler shear force in beef top loin steaks. J. Muscle Foods. 2:289-296.

Shackelford, S.D., T.L. Wheeler, and M. Koohmaraie. 1995. Relationship between shear force and trained sensory panel tenderness ratings of 10 major muscles from Bos indicus and Bos taurus cattle. J. Anim. Sci. 73:3333-3340. 
Shackelford, S.D., T.L. Wheeler, and M. Koohmaraie. 1997. Tenderness classification of beef: I. Evaluation of beef longissimus shear force at 1 or 2 days postmortem as a predictor of aged beef tenderness. J. Anim. Sci. 75:2417-2422.

Shackelford, S.D., T.L. Wheeler, and M. Koohmaraie. 1999. Tenderness classification of beef: II. Design and analysis of a system to measure beef longissimus shear force under commercial processing conditions. J. Anim. Sci. 77:1474-1481.

Shanks, B.C., D.M. Wulf, and R.J. Maddock. 2002. Technical note: The effect of freezing on Warner-Bratzler shear force values of beef longissimus steaks across several postmortem aging periods. J. Anim. Sci. 80:2122-2125.

Smith, G.C., Z.L. Carpenter, and G.T. King. 1969. Considerations for beef tenderness evaluations. J. Food Sci. 34:612-618.

Smith, G.C., G.R. Culp, and Z.L. Carpenter. 1978. Postmortem aging of beef carcasses. J. Food Sci. 43:823-826.

Smith, G.C., Z.L. Carpenter, H.R. Cross, C.E. Murphey, H.C. Abraham, J.W. Savell, G.W. Davis, B.W. Berry, and F.C. Parrish, Jr. 1985. Relationship of USDA marbling groups to palatability of cooked beef. J. of Food Quality. 7:289-308.

Stipanuk, M.H. 2000. Biochemical, physiological, and molecular aspects of human nutrition. Saunders Elsevier, St. Louis, MO. 2:22.

Stromer, M.H., D.E. Goll, and L.E. Roth. 1967. Morphology of rigor-shortened bovine muscle and the effect of trypsin on pre- and postrigor myofibrils. J. Cell Biol. 34:431-445.

Szczesniak, A.S. and K.W. Jorgeson. 1965. Methods of meat texture measurement viewed from the background of factors affecting tenderness. Adv. Food Res. 14:33.

Takahashi, K., T. Fukazawa, and T. Yasui. 1967. Formation of myofibrillar fragments and reversible contraction of sarcomeres in chicken pectoral muscle. J. Food Sci. 32:409-413.

Tatum, J.D., K.E. Belk, M.H. George, and G.C. Smith. 1999. Identification of quality management practices to reduce the incidence of retail beef tenderness problems: Development and evaluation of a prototype quality system to produce tender beef. J. Anim. Sci. 77:2112-2118. 
Taylor, R.G., G.H. Geesink, V.F. Thompson, M. Koohmaraie, and D.E. Goll. 1995. Is Z-disk degradation responsible for postmortem tenderization? J. Anim. Sci. 73:1351-1367.

USDA. 1996. Institutional Meat Purchase Specifications for Fresh Beef. Agric. Marketing Serv., USDA, Washington DC.

USDA. 2004. USDA National Nutrient Database for Standard Reference, Release 16-1. Nutrient Data Laboratory Home Page, http://www.nal.usda.gov/fnic/foodcomp.

USDA. 2005. Market News Report: National weekly boxed beef cut out and boxed beef cuts. LM XB 459. Des Moines, IA; Agricultural Marketing Service, USDA.

USDA. 2006. USDA Nutrient Database for Standard Reference, Release 19. www.ars.usda.gov/nutrientdata.

USDA. 2007. USDA Nutrient Database for Standard Reference. Release 20.

USDA. 2008. Composition of Foods Raw, Processed, Prepared USDA National Nutrient Database for Standard Reference, Release 20.

Uytterhaegen, L., E. Claeys, and D. Demeyer. 1994. Effects of exogenous protease effectors on beef tenderness development and myofibrillar degradation and solubility. J. Anim. Sci. 72:1209-1223.

Von Seggern, D.D., C.R. Calkins, D.D. Johnson, J.E. Brickler, and B.L. Gwartney. 2005. Muscle profiling: Characterizing the muscles of the beef chuck and round. Meat Sci. 71:39-51.

Wahle, K.W.J., S.D. Heys, and D. Rotondo. 2004. Conjugated linoleic acids: are they beneficial or detrimental to health? Prog. Lipid Res. 43:553-587.

Wahrmund-Wyle, J.L., K.B. Harris, and J.W. Savell. 2000. Beef retail cut composition: 2. Proximate analysis. J. Food Compos. Anal. 13:243-251.

Wang, K. and R. Ramirez-Mitchell. 1983. A network of transverse and longitudinal intermediate filaments is associated with sarcomeres of adult vertebrate skeletal muscle. J. Cell Biol. 96:562-570.

Wheeler, T.L. and M. Koohmaraie. 1994. Prerigor and postrigor changes in tenderness of ovine longissimus muscle. J. Anim. Sci. 72:1232-1238. 
Wheeler, T.L., M. Koohmaraie, L.V. Cundiff, and M.E. Dikeman. 1994. Effects of cooking and shearing methodology on variation in Warner-Bratzler shear force values in beef. J. Anim. Sci. 72:2325-2330.

Wheeler, T.L., S.D. Shackelford, L.P. Johnson, M.F. Miller, R.K. Miller, and M. Koohmaraie. 1997a. A comparison of Warner-Bratzler shear force assessment within and among institutions. J. Anim. Sci. 75:2423-2432.

Wheeler, T.L., S.D. Shackelford, and M. Koohmaraie. 1997b. Standardizing collection and interpretation of Warner-Bratzler shear force and sensory tenderness data. Proc. 50 ${ }^{\text {th }}$ Annu. Recip. Meat Conf. Natl. Livest. and Meat Board, Chicago, IL. 68-77.

Whipple, G., M. Koohmaraie, M.E. Dikeman, J.D. Crouse, M.C. Hunt, and R.D. Klemm. 1990. Evaluation of attributes that affect longissimus muscle tenderness in Bos taurus and Bos indicus cattle. J. Anim. Sci. 68:2716-2728.

Willett, W.C., M.J. Stampfer, G.A. Colditz, B.A. Rosner, and F.E. Speizer. 1990. Relation of meat, fat, and fiber intake to the risk of colon cancer in a prospective study among women. New Engl. J. Med. 323:1664-1672. 


\section{CHAPTER VI}

\section{APPENDIX}


Appendix 1.1. Least squares means \pm standard errors for Warner-Bratzler shear force $(\mathrm{kg})$ of four beef muscles at seven postmortem aging periods $(\mathrm{d})^{1}$

Days postmortem

\begin{tabular}{|c|c|c|c|c|c|c|c|}
\hline \multirow[b]{2}{*}{ Muscle } & \\
\hline & 2 & 4 & 6 & 10 & 14 & 21 & 28 \\
\hline Adductor & $4.38 \pm .09^{\mathrm{a}}$ & $4.26 \pm .09^{\mathrm{ab}}$ & $4.03 \pm .09^{b}$ & $3.68 \pm .09^{c}$ & $3.71 \pm .09^{c}$ & $3.55 \pm .09^{\mathrm{cd}}$ & $3.44 \pm .09^{\mathrm{d}}$ \\
\hline Gastrocnemius & $4.64 \pm .10^{\mathrm{a}}$ & $4.55 \pm .10^{\mathrm{a}}$ & $4.09 \pm .10^{\mathrm{b}}$ & $3.89 \pm .10^{\mathrm{bc}}$ & $3.75 \pm .10^{\mathrm{cd}}$ & $3.54 \pm .10^{\mathrm{d}}$ & $3.61 \pm .10^{\mathrm{d}}$ \\
\hline Pectineus & $3.75 \pm .09^{\mathrm{a}}$ & $3.63 \pm .09^{\mathrm{ab}}$ & $3.44 \pm .09^{\mathrm{bc}}$ & $3.43 \pm .09^{\mathrm{bc}}$ & $3.26 \pm .09^{\mathrm{cd}}$ & $3.08 \pm .09^{\mathrm{de}}$ & $2.87 \pm .09^{\mathrm{e}}$ \\
\hline Superficial digital flexor ${ }^{2}$ & $10.84 \pm .67^{\mathrm{ab}}$ & $11.00 \pm .68^{\mathrm{ab}}$ & $11.60 \pm .68^{\mathrm{ab}}$ & $10.96 \pm .68^{\mathrm{ab}}$ & $10.01 \pm .67^{\mathrm{b}}$ & $11.16 \pm .67^{\mathrm{ab}}$ & $11.84 \pm .68^{\mathrm{a}}$ \\
\hline
\end{tabular}

${ }^{1}$ Within an age subclass, LSD $(P<0.05)$.

${ }^{2}$ Within an age subclass, LSD $(P>0.05)$.

${ }^{\text {abcde }}$ Within a row, means without a common superscript letter differ $(P<0.05)$. 
Appendix 1.2. Least squares means \pm standard errors for Warner-Bratzler shear force $(\mathrm{kg})$ for USDA Select and premium USDA Choice Gracilis at seven postmortem aging periods (d) ${ }^{1}$

\begin{tabular}{|c|c|c|c|c|c|c|c|}
\hline \multirow[b]{2}{*}{ Gracilis } & \multicolumn{7}{|c|}{ Days postmortem } \\
\hline & 2 & 4 & 6 & 10 & 14 & 21 & 28 \\
\hline USDA Select & $6.34 \pm .14^{\mathrm{a}}$ & $5.78 \pm .14^{\mathrm{b}}$ & $5.51 \pm .14^{\mathrm{b}}$ & $4.97 \pm .14^{\mathrm{c}}$ & $4.61 \pm .14^{\mathrm{d}}$ & $4.24 \pm .14^{\mathrm{e}}$ & $4.16 \pm .14^{\mathrm{e}}$ \\
\hline Premium USDA Choice & $5.58 \pm .14^{\mathrm{a}}$ & $5.49 \pm .14^{\mathrm{a}}$ & $4.89 \pm .14^{\mathrm{b}}$ & $4.69 \pm .14^{\mathrm{b}}$ & $4.27 \pm .14^{\mathrm{c}}$ & $4.05 \pm .14^{\mathrm{c}}$ & $4.02 \pm .14^{\mathrm{C}}$ \\
\hline
\end{tabular}

${ }^{1}$ Within a grade subclass, LSD $(P<0.05)$, within an age subclass, LSD $(P<0.05)$.

${ }^{\text {abcde }}$ Within a row, means without a common superscript letter differ $(P<0.05)$ 
Appendix 2.1. Analysis averages of raw proximate, cholesterol, and fatty acid (normalized weight percentage (\%)) $)^{\mathrm{a}}$ test standards

\begin{tabular}{|c|c|c|c|c|c|c|c|c|c|c|c|c|c|c|c|c|}
\hline \multicolumn{3}{|c|}{ Standard } & \multicolumn{3}{|c|}{ Dry Matter, \% } & \multicolumn{2}{|c|}{ Moisture, \% } & \multicolumn{2}{|c|}{ Ash, \% } & \multicolumn{2}{|c|}{ Lipid, \% } & \multicolumn{2}{|r|}{ Protein, \% } & \multicolumn{3}{|c|}{ Cholesterol, mg/100g } \\
\hline Inter & & & & .339 & & 79.76 & & & & & 90 & & 11.761 & & .600 & \\
\hline USD & Beef & & & .116 & & 84.88 & & & & & 00 & & 12.448 & & 7.020 & \\
\hline USD & A Chick & & & .503 & & 83.49 & & & & & 64 & & 12.384 & & 4.300 & \\
\hline Standard & C14:0 & C14:1 & C16:0 & C16:1 & C17:0 & C17:1 & C18:0 & $\begin{array}{c}\text { t- } \\
\text { vaccenic }\end{array}$ & C18:1c9 & C18:1c11 & C18:2 & C18:3 & C18:2c9t11 & C18:2t10c12 & C20:4 & C24:0 \\
\hline $\begin{array}{l}\text { Internal- } \\
\text { USDA }\end{array}$ & 0.2693 & 0.0641 & 2.5551 & 0.3239 & 0.1418 & 0.0945 & 1.7361 & 0.3655 & 3.9766 & 0.1849 & 0.4067 & 0.0189 & 0.0323 & 0.0032 & 0.0540 & 0.0091 \\
\hline $\begin{array}{l}\text { Beef- } \\
\text { USDA }\end{array}$ & 0.0953 & 0.0240 & 1.0881 & 0.1371 & 0.0588 & 0.0415 & 0.7455 & 0.1273 & 2.5288 & 0.0915 & 0.2966 & 0.0179 & 0.0157 & 0.0020 & 0.0511 & 0.0086 \\
\hline \multirow{2}{*}{ Chicken- } & 0.1867 & 0.0430 & 1.8348 & 0.2344 & 0.0992 & 0.0684 & 1.1906 & 0.2143 & 2.8505 & 0.1364 & 0.3561 & 0.0108 & 0.0220 & 0.0033 & 0.0488 & 0.0100 \\
\hline & 0.2808 & 0.0766 & 2.5554 & 0.3687 & 0.1305 & 0.0944 & 1.5524 & 0.3446 & 3.8213 & 0.1927 & 0.4278 & 0.0200 & 0.0353 & 0.0021 & 0.0691 & 0.0113 \\
\hline MHA & 0.2424 & 0.0609 & 2.3003 & 0.3205 & 0.1214 & 0.0883 & 1.4302 & 0.3016 & 3.4797 & 0.1739 & 0.4229 & 0.0205 & 0.0297 & 0.0048 & 0.0701 & 0.0112 \\
\hline
\end{tabular}

${ }^{\mathrm{a}}$ Data is reported as the normalized weight percentage of fatty acid. 
